Frontiers in Heat Pipes

\title{
A REVIEW OF HEAT PIPE APPLICATION INCLUDING NEW OPPORTUNITIES
}

\author{
Masataka Mochizuki*, Thang Nguyen, Koichi Mashiko, Yuji Saito, Tien Nguyen and Vijit Wuttijumnong
}

Fujkura Ltd. 1-5-1, Kiba, Koto-Ku, Tokyo 135-8512, Japan

\begin{abstract}
This paper contained a detail review of heat pipe application ranging from computer electronics to renewable energy. In computer electronics application, the trend of the computer processors performance and power consumption has been increased significantly each year. Heat dissipation has been increased but in contrast the size of die on the processor has been reduced or remained the same size due to nano-size circuit technology and thus the heat flux is critically high. The heat flux was about $10-15 \mathrm{~W} / \mathrm{cm}^{2}$ in the year 2000 and had reached over $100 \mathrm{~W} / \mathrm{cm}^{2}$ in 2010 . The purpose of this paper is to provide insight into how to extend the air cooling capability and maximize its performance by use of heat pipes.

The global warming crisis is real, and it is a responsibility for all individuals to put forth effort to reduce and prevent further damage to the global environment. In most countries worldwide, the majority of electric power is generated from non-renewable energy sources including coal, gas, and nuclear power, which degrade earth's atmosphere by green house gas emissions. With the use of heat pipes can minimize carbon emissions to the environment. Some applications presented and discussed in this paper are collecting natural cold energy and storing it for cooling of data centers and agricultural products, cooling concentrated photo voltaic cells using Phase Change Material and night sky radiation cooling, use of heat pipes to prevent iceberg and glacier melting, collection of solar heat for road snow melting, use of large-scale heat pipes for extraction of geothermal heat, and use of ultra-large-scale heat pipes for cooling and maintaining the earth's temperature.
\end{abstract}

Keywords: cooling electronics, computer processor, global warming, data center, heat pipe, thermo-siphon, artificial permafrost storage

\section{INTRODUCTION}

For the current desktop and server processors, the heat dissipation, in general, exceeds $100 \mathrm{~W}$ and the heat flux could be more than 100 $\mathrm{W} / \mathrm{cm}^{2}$. Passive cooling is no longer appropriate to deliver the cooling requirement. Other technologies such as liquid cooling, thermoelectric cooling, and refrigeration can deliver the required thermal performance, and have been put into practical use for cooling of high performance computers. However, these cooling options have not yet been widely used because of the integration complexity of the system, limited reliability life data, yet limited availability of high volume manufacturing capability, and especially the higher cost. The cooling technology that is still most widely used in cooling for computers is air cooling, because this is a mature technology with the least operation and lowest costs.

The processor's die surface where the heat is generated is usually small approximately $1 \mathrm{~cm}^{2}$. For effective cooling should required least temperature gradient between the heat source and radiating components. The best-known devices for effective heat transfer with lowest thermal resistance are the heat pipes and vapor chambers. Basically, the heat pipes and vapor chambers are two phase heat transfer devices, is an evacuated and sealed container which contains a small quantity of working fluid. One end of the container is heated, causing the liquid to vaporize and the vapor to move to the cold end and condense. As the latent heat of evaporation is large, considerable quantities of heat can be transported with a very small temperature difference from end to end. Thus, it is a device of very high thermal conductance. Its equivalent thermal conductivity can be several hundred times than that of a solid copper device of the same dimensions.
For the data centers electric power consumption is a major operational cost. As the power supplied to the data center processing units is ultimately dissipated as heat, a significant fraction of data center power is used to cool these units (Brill, 2010; Schmidt et al., 2005). It is estimated that for every watt of power consumed by the computing infrastructure, another one-third to half watt is needed to operate the cooling infrastructure. For example, an average data center with thermal load output of $8800 \mathrm{~kW}$ consumes more than $\$ 4$ million a year just for cooling purposes. Furthermore, the data center electricity consumption nearly doubles every 5 years. In most countries worldwide, a major portion of the electric power is generated from nonrenewable energy sources including coal, gas, and nuclear power, which degrade earth's atmosphere by green-house gas emissions. In this regard, energy conservation based on cooling systems for data centers can provide two-fold advantages, first by reducing electricity consumption and thus operational costs for thermal management and second by minimizing the carbon emissions in the environment (Patel et al., 2002; Moore et al.; Schmidth et al., 2009). In the present paper, design, thermal analysis, and economics of the proposed heat-pipebased cold energy storage system are discussed in detail and compared with the existing chiller using a refrigeration system.

This paper includes designs, data, and discussions of various fan sink air cooling designs showing how the design changed to push the limit of the air cooling capability. For examples, heat sink design pushed to the limit to maximize heat transfer surface areas, improving fin efficiency, fan air flow optimization, and the use of heat pipes or vapor chambers to improve spreading and heat transfer. The use of the three dimensions thermal management device not only reduced the physical form factor of the solution but also enable the processors to 
operate at its full performance. The utilization of the two-phase fluid phenomena to spread the heat was a key factor to be the leader of extending the air cooling limit capability for high performance computers. Authors include recommendation of what and which way we are going to develop for next generation of high power cooling chips.

This paper also presents numerous concepts of using heat pipes to collect available natural energy and using it for applications without the need for electricity. Some of the concepts have been tried in the past but have not been widely used in practical applications, but with current increased concerns regarding global warming environmental issues, these concepts can become feasible solution.

\section{HEAT PIPE REVOLUTION}

Heat pipes have been used in various applications for decades. New applications have emerged with time as shown below. The authors believed that heat pipes will soon be widely used in preventing global warming.

1970 Aerospace and Astronautics

1980 Energy Conservation

1990 Industrial Use and Natural Energy Utilization

2000 Computers and Electronics Cooling

2010 Global Warming and the Environment ???

Currently the greatest use of heat pipes is in the cooling of computers and electronic products. The authors believed that approximately 15 million pieces of heat pipes are produced per month worldwide for these applications. There are mainly three types of heat pipes as shown in Fig. 1 - grooved, sintered or composited wick heat pipes.

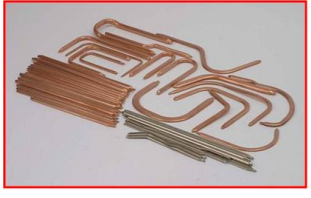

Axially Grooved

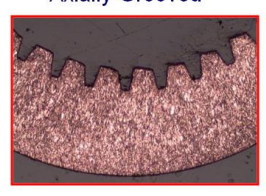

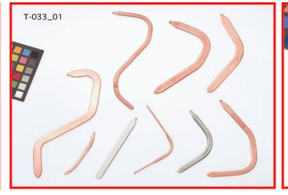

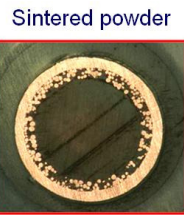

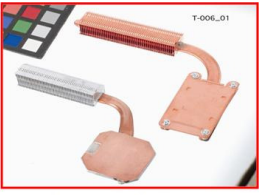

Composited
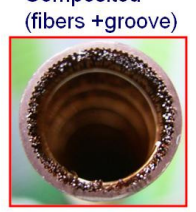

Fig. 1 Types of heat pipes

Figure 2 shows an overview of the application of heat pipes. The principle is to use the heat pipe to effectively transfer and spread the heat to a larger surface for cooling.

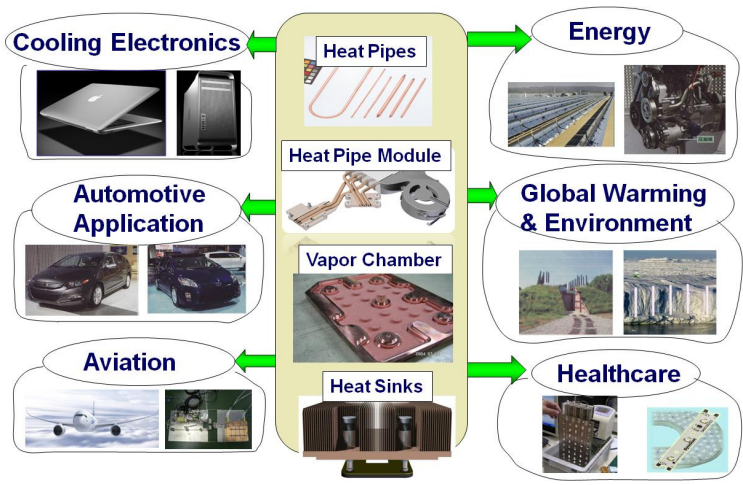

Fig. 2 Heat pipe application

\section{HEAT PIPE APPLICATION IN COMPUTER AND ELECTRONICS}

Heat pipes and vapor chambers have emerged as the most significant technology and cost-effective thermal solution owing to their excellent heat transfer capabilities, high efficiency and structure simplicity. A selection of the working fluid is based on the operating temperature of the application. In computer applications, the operating temperatures are normally between 50 and $100{ }^{\circ} \mathrm{C}$. Within this temperature range water is the best working fluid. The utilization of heat pipes and vapor chamber to spread and transfer the heat was a key factor for extending the air cooling limit capability for high performance computers.

\subsection{Formulation}

A basic formulation to calculate the thermal resistance required for the cooling solution is as follows:

$\mathrm{R}_{\mathrm{ja}}=\mathrm{R}_{\mathrm{jc}}+\mathrm{R}_{\mathrm{ca}}=\left(\mathrm{T}_{\mathrm{j}}-\mathrm{T}_{\mathrm{a}}-\mathrm{T}_{\mathrm{sys}}\right) / \mathrm{Q}$

Where,

$\mathrm{Q}=$ Heat dissipation $[\mathrm{W}]$

$\mathrm{R}_{\mathrm{ja}}=$ Thermal resistance from the CPU die to ambient $\left[{ }^{\circ} \mathrm{C} / \mathrm{W}\right]$.

$\mathrm{R}_{\mathrm{jc}}=$ Thermal resistance from the CPU die to CPU case surface $\left[{ }^{\circ} \mathrm{C} / \mathrm{W}\right]$.

$\mathrm{R}_{\mathrm{ca}}=$ Thermal resistance from CPU case surface to ambient $\left[{ }^{\circ} \mathrm{C} / \mathrm{W}\right]$.

$\mathrm{T}_{\mathrm{a}}=$ Ambient temperature $\left[{ }^{\circ} \mathrm{C}\right]$.

$\mathrm{T}_{\mathrm{j}}=$ Junction temperature inside die $\left[{ }^{\circ} \mathrm{C}\right]$.

$\mathrm{T}_{\text {sys }}=$ Temperature rise of the ambient inside the system due to other heat generating components (eg. hard disk drive; graphic cards etc..) $\left[{ }^{\circ} \mathrm{C}\right]$.

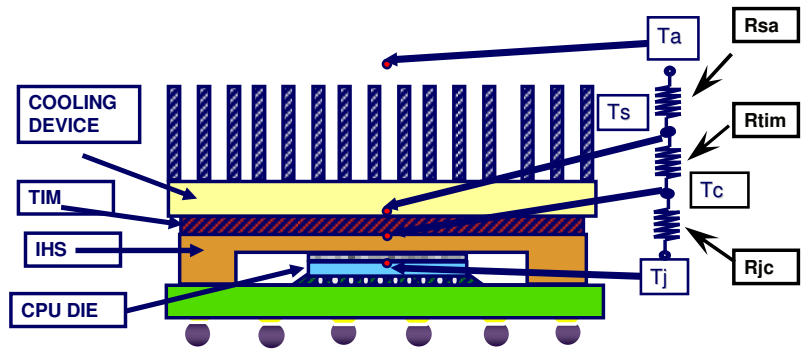

(a) Schematic of thermal resistance

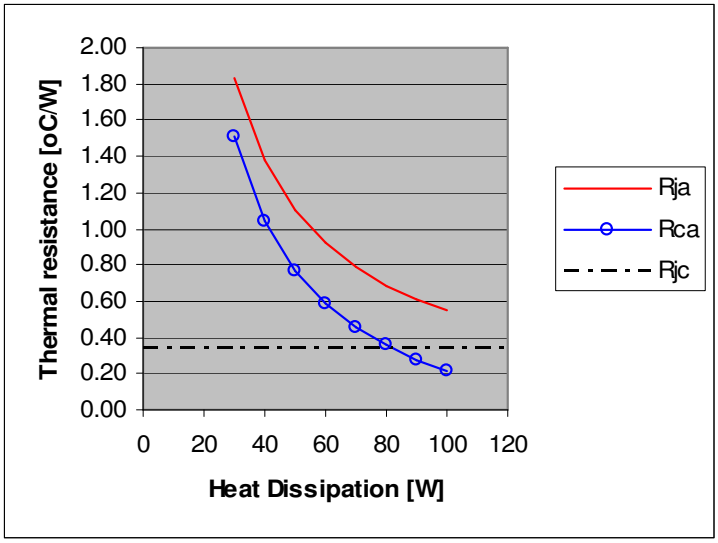

(b) $\mathrm{R}_{\mathrm{ja}}, \mathrm{R}_{\mathrm{jc}}$, and $\mathrm{R}_{\mathrm{ca}}$ vs. heat dissipation

Fig. 3 Thermal resistances 
In the case of CPU packaged with an integrated heat spreader, the $\mathrm{R}_{\mathrm{jc}}$ varies depending on the type of CPU and the manufacturers. In most cases, the $\mathrm{R}_{\mathrm{jc}}$ is approximately $0.33{ }^{\circ} \mathrm{C} / \mathrm{W}$.

The thermal solution provider could only control the $\mathrm{R}_{\mathrm{ca}}$. This thermal resistance consisted of the thermal interface material and the cooling solution. Figure 3(a) shows the thermal resistance network, and Fig. 3(b) shows the required thermal resistance $R_{j a}, R_{j c}$ and $R_{c a}$ versus heat dissipation. Assuming that for maximum CPUs the junction temperature is $100{ }^{\circ} \mathrm{C}$, the outside ambient temperature is $35{ }^{\circ} \mathrm{C}$, and system temperature rise of $10{ }^{\circ} \mathrm{C}$. When the power goes up to $100 \mathrm{~W}$, $R_{\text {ja }}\left(0.33{ }^{\circ} \mathrm{C} / \mathrm{W}\right)$ cannot be neglected because external thermal margin $\left(R_{\mathrm{ca}}\right)$ almost reaches the limit of air cooling.

Figure 4 shows general magnitude cooling capability comparison between air and liquid cooling. It showed the heat transfer capability of liquid cooling can be 6 times more than air cooling.

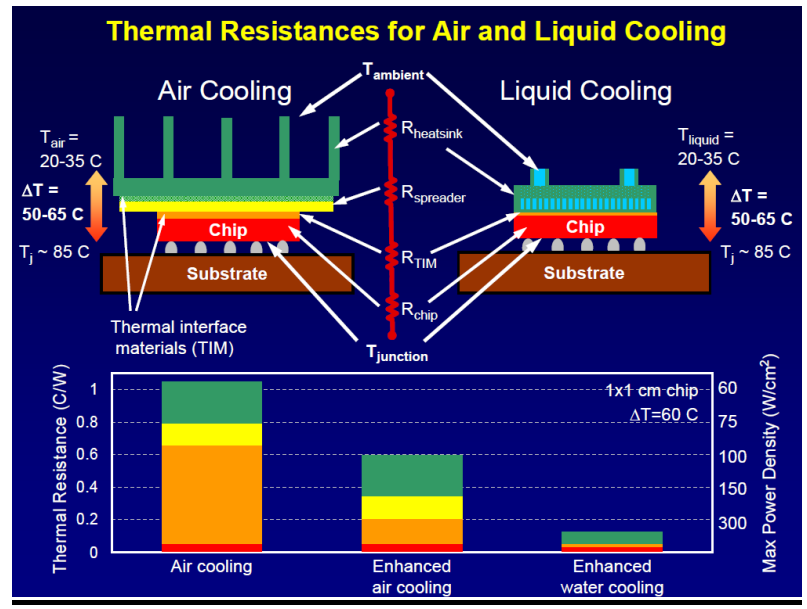

Fig. 4 Thermal performance comparison between air cooling and liquid cooling

\subsection{Examples of notebook thermal solution}

\section{2(a) Hybrid system}

Figure 5 shows the hybrid system consisted of heat pipes, die cast plate, fins, and fans (not shown). The two heat pipes were used to spread heat on the aluminum die cast plate. Aluminum fins attached to the heat pipe and radial fans were used to blow air directly through fins. The $\mathrm{R}_{\mathrm{ca}}$ of this system was about $1.2^{\circ} \mathrm{C} / \mathrm{W}$ and capable of dissipating $35 \mathrm{~W}$.

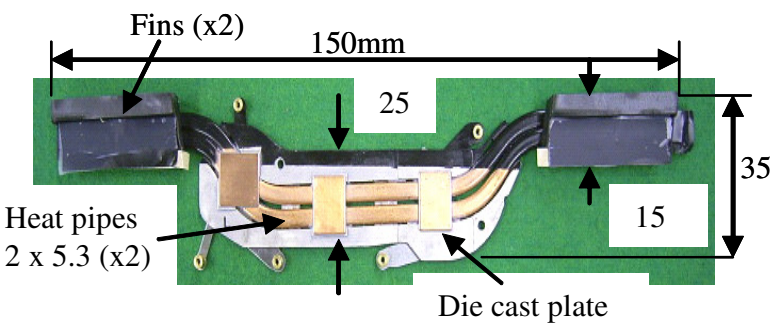

Fig. 5 Hybrid cooling system

\section{2(b) Remote heat exchanger}

Basically, the remote heat exchanger consisted of heat pipe, fin, and fan as shown in Fig. 6. The fan size is approximately $45 \mathrm{~mm} \times 45 \mathrm{~mm}$ and $10 \mathrm{~mm}$ thick. The fan airflow was estimated to be $0.15 \mathrm{~m}^{3} / \mathrm{min}$ at $0 \mathrm{~Pa}$ and $90 \mathrm{~Pa}$ at $0 \mathrm{~m}^{3} / \mathrm{min}$ when tested in an open environment. The ${ }_{\mathrm{Rca}}$ for this design is approximately $1{ }^{\circ} \mathrm{C} / \mathrm{W}$, with a cooling capacity about $42 \mathrm{~W}$. Figure 7 shows examples of various remote heat exchanger designs.

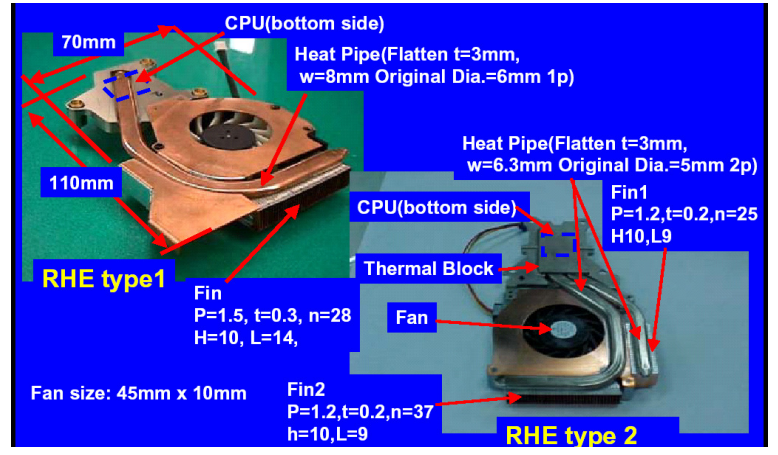

Fig. 6 Remote heat exchanger

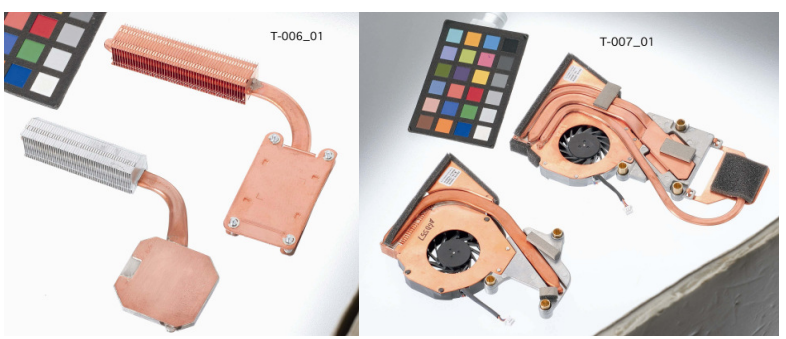

Fig. 7 Examples of various remote heat exchangers designs

\section{2(c) Vapor chamber}

The principle of operation of a vapor chamber is similar to a heat pipe, which is a two-phase heat transfer device. A heat pipe is made of a round pipe, and after sealing the ends can be bent and flattened to the required shape. The vapor chamber container can be made by stamping, cold forging, or machining processes, so that the shape is fixed and it cannot be bent or flattened. Figure 8 shows the shapes and sizes of various vapor chambers.

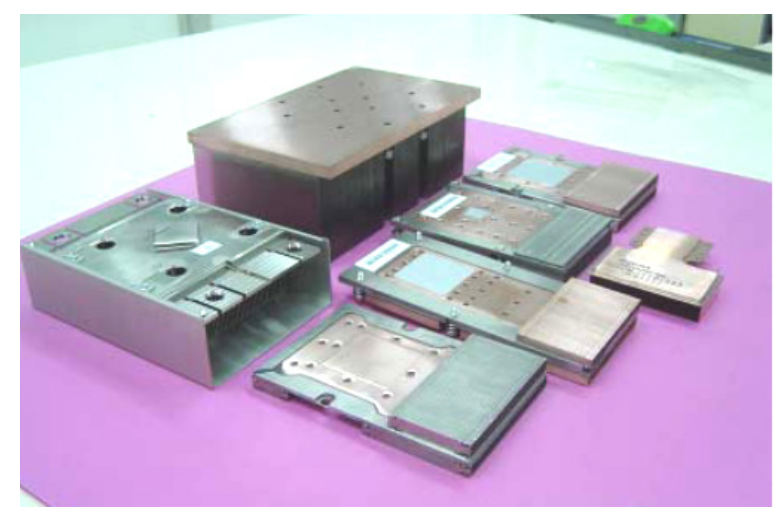

Fig. 8 Examples of various shapes and sizes of vapor chamber

An example of a vapor chamber solution is shown in Fig. 9. The $\mathrm{R}_{\mathrm{ca}}$ of this system is about $0.3{ }^{\circ} \mathrm{C} / \mathrm{W}$. When it is assumed that the boundary condition is $\mathrm{T}_{\mathrm{j}}=100{ }^{\circ} \mathrm{C} ; \mathrm{T}_{\mathrm{a}}=35^{\circ} \mathrm{C}$; $\mathrm{T}_{\text {sys }}=10{ }^{\circ} \mathrm{C}$; and $\mathrm{R}_{\mathrm{jc}}=0.33{ }^{\circ} \mathrm{C} / \mathrm{W}$, then this system can dissipate heat of $87 \mathrm{~W}$. 


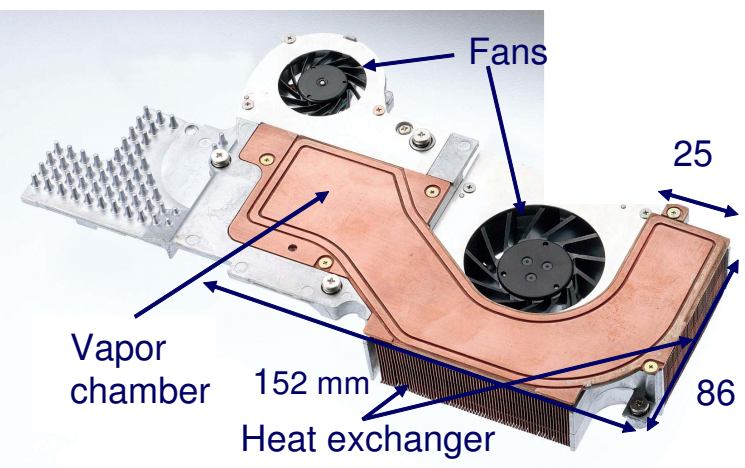

Fig. 9 Vapor chamber solution

The performance of vapor chamber is better than a heat pipe because of the two-dimensional heat transfer element. The advantages of vapor chamber solution compared with heat pipe solution are given as follows:

- Heat flow is two-dimensional as compared with onedimensional flow in a heat pipe. This gives vapor chamber a higher heat transfer and lower thermal resistance.

- Higher heat flux capability of over $50 \mathrm{~W} / \mathrm{cm}^{2}$.

- Vapor chamber has uniform temperature distribution, large body surface area so it is excellent for heat dissipation.

- Vapor chamber can be placed directly in contact with the CPU (via thermal interface material), eliminating conducting and contacting resistance of the "heat block" to which heat pipe is attached.

- $\quad$ Fins can be attached directly to the vapor chamber, having higher surface of contact thus, it can reduce contact resistance and increased fin efficiency.
Figure 10 shows the trend of thermal solution in laptop PCs. It is evident that to maximize the performance and to push the limit of the air cooling capability, the design needs multiple heat pipes or vapor chambers with high-density packed fins and multiple fans.

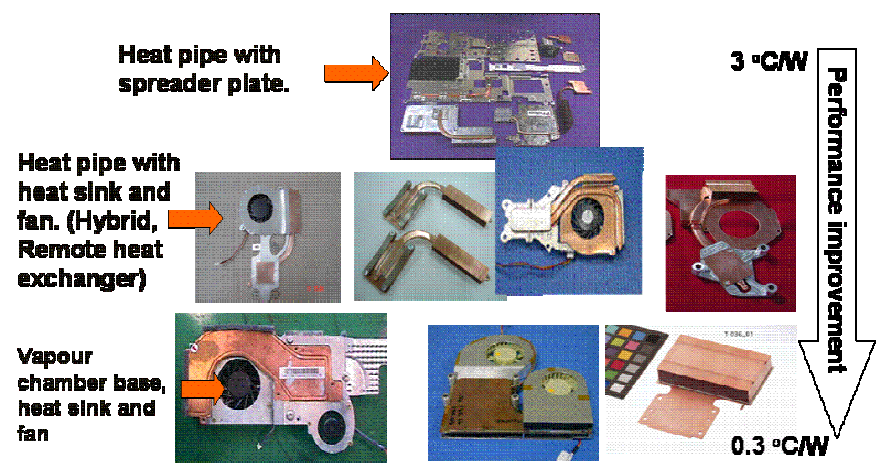

Fig. 10 Trend of thermal solution in laptop

\subsection{Examples of desktop thermal solution}

Figure 11 shows a summary of design changes to maximize the air cooling capability. For equal comparison all the designs are within the boundary of a cooling volume of approximately $90 \mathrm{~mm}$ x $90 \mathrm{~mm} \times 65$ $\mathrm{mm}$ height. The acoustic level at the maximum specification in general is $45 \mathrm{~dB}$ at $1 \mathrm{~m}$ from the source. Description of the design is give below.

- Type 1: Normal extrusion heat sink with fins of count approximately 7 fins per inch, $1.2 \mathrm{~mm}$ fin thickness, pitch 3.5 $\mathrm{mm}$ and $30 \mathrm{~mm}$ tall. The $\mathrm{R}_{\mathrm{ca}}$ range is 0.4 to $0.5^{\circ} \mathrm{C} / \mathrm{W}$.

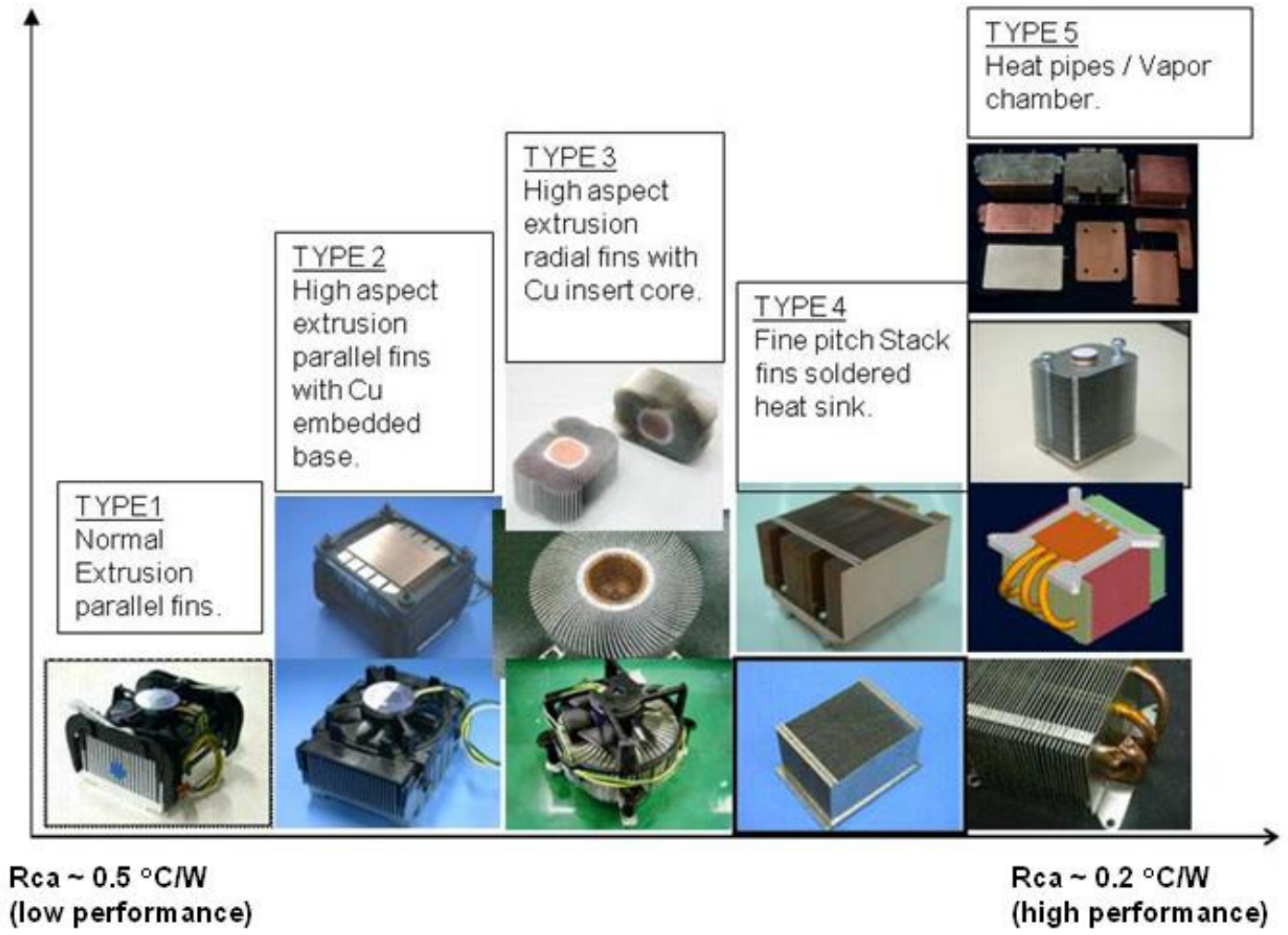

Fig. 11 Summary of thermal design trend for cooling desktop PCs 
- Type 2: High aspect extrusion heat sink. In this design extrusion had been pushed to the limit capability. Fins count approximately 10 fins per inch, $1 \mathrm{~mm}$ fin thickness, pitch 2.3 $\mathrm{mm}$ pitch and $30 \mathrm{~mm}$ tall. The aluminum base had a copper block soldered to minimize the heat spreading resistance. The $\mathrm{R}_{\text {ca }}$ range is 0.3 to $0.4{ }^{\circ} \mathrm{C} / \mathrm{W}$.

- Type 3: The design changes from parallel fin extrusion to radial type extrusion. The heat sink core has an integrated $\mathrm{Cu}$ core to improve heat conduction from base to fins. In general radial fins could capture the air from the fan better than a parallel plate fin, thus providing higher fin-air heat transfer coefficient and more efficient cooling. The $\mathrm{R}_{\mathrm{ca}}$ approx. 0.3 to $0.35{ }^{\circ} \mathrm{C} / \mathrm{W}$.
- $\quad$ Type 4: High density stack fins were soldered to metal base. The fin thickness can be as thin as $0.2 \mathrm{~mm}$, and fin gap less than $1 \mathrm{~mm}$. The $\mathrm{R}_{\mathrm{ca}}$ approximately 0.25 to $0.3^{\circ} \mathrm{C} / \mathrm{W}$.

- Type 5: For further reduction in $\mathrm{R}_{\mathrm{ca}}$ less than $0.25^{\circ} \mathrm{C} / \mathrm{W}$ for the same constraint specification, there would be a need to consider the use of the bases of heat pipes or vapor chambers to maximize the heat transfer from source to fins for improvement in cooling.

Figure 12 shows an example of how heat pipes were used to improve the thermal performance. Heat pipes were used to transfer heat effectively from the heat source to fins, improve the fin efficiency and reduce spreading resistance at the base.
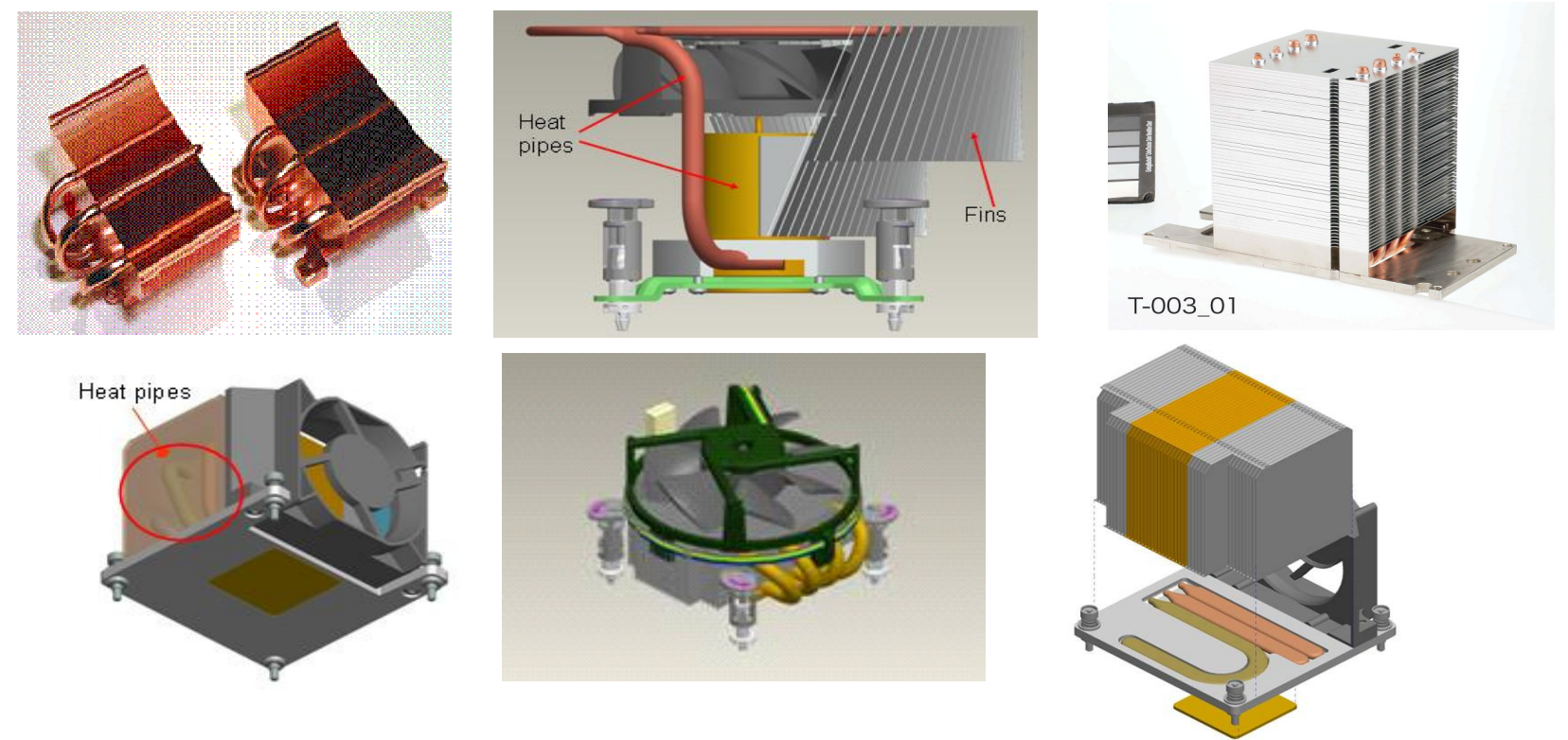

Fig. 12 Examples of heat pipe heat sink thermal designs for cooling desktop PCs

\subsection{Thermal solution for graphic processor}

Figure 13 shows the advance high performance three dimensions thermal management device to provide the ultra cooling for the high performance graphic cards. This three dimensions thermal management device is structured based on spreading the heat dissipation from the Graphic Processor Unit, GPU, in the horizontal plane through the use of the advanced technology of Vapor chamber. Furthermore, the dissipated heat was elevated to the vertical dimension through the use of the two auxiliary heat pipes. This advance thermal solution to ensure maximum cooling possibilities for graphic cards in the smallest form factor for to deliver the top designed performance. Vapor chamber is a two-phase water working fluid device. It is a totally sealed device, passive and no moving parts. Vapor chamber uses the latent heat of vaporization to transfer the heat, so it has extremely high thermal conductance compared to any known solid metal. The use of the three dimensions management device not only reduced the physical form factor of the solution but also enable the GPU to operate at its full performance. The utilization of the two-phase fluid phenomena to spread the heat was a key factor for extending the air cooling limit.

The key points of the advantages of this thermal device as follows:

- Advanced and optimised wick structures internal of vapor chamber to enhance the heat transfer and maximise the heat transfer rate. Heat flux capability over $75 \mathrm{~W} / \mathrm{cm}^{2}$.

- Thermal spreading resistance in the base which attach to the die of the graphic card can be reduced by approximately half when compared to solid $\mathrm{Cu}$ base of the same size.
- Combination of vapor chamber with heat pipes to maximize the heat transfer and fin efficiency.

- Overall thermal performance is $0.05{ }^{\circ} \mathrm{C} / \mathrm{W}$ better than the design with solid $\mathrm{Cu}$ base and heat pipe.

- Isothermal surface characteristics of vapor chamber introduced a well uniformed heat distribution on the GPU which empower the users to over to have the ultimate Performance from the GPU.

Thermal performance of the combine vapor chamber and heat pipe for cooling graphic card is shown in Fig. 14. It is anticipated that the thermal performance could be improved approximately $0.05{ }^{0} \mathrm{C} / \mathrm{W}$. This means that for $100 \mathrm{~W}$ input the processor could operate $5{ }^{\circ} \mathrm{C}$ lower. Operating the processor at lower temperature would enhance its performance and reliability.

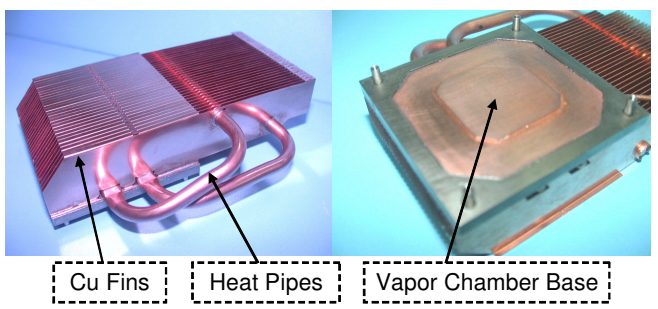

Fig. 13 Vapor chamber and heat pipe thermal solution for cooling high performance graphic processors 


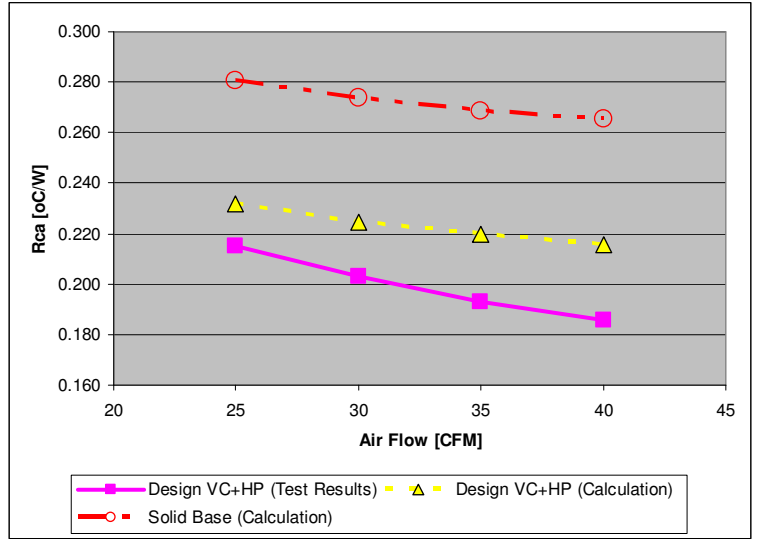

Fig. 14 Thermal performance of vapour chamber and heat pipe thermal solution for cooling high performance graphic processors

\subsection{Thermal solution using piezo fan}

Another air cooling technology is piezo fan for thermal management of low form factor, low power consumption and low noise devices. Examples of such devices are in the mobile market such as PDA, phones, music players, portable gaming and so on. The traditional rotary axial fan or blower may not be suitable due to space, power consumption and noise constraints. The basic principle of piezo fan is shown in Fig. 15. A long metal or plastic blade is bonded to a piezoelectric material in a cantilever fashion. When electrics applied to a piezo layer the randomly oriented ions in the piezo materials go into alignment, which will cause deformation of the piezo layer. Under an alternating current the blade vibrates back and forth with the same frequency as the alternating current. The vibration generates air flow which can be used for air cooling. The larger the vibration, the larger air flow and in turn provide better cooling. The piezo fan can be placed in front of the heat sink to provide cooling air through the heat sink.

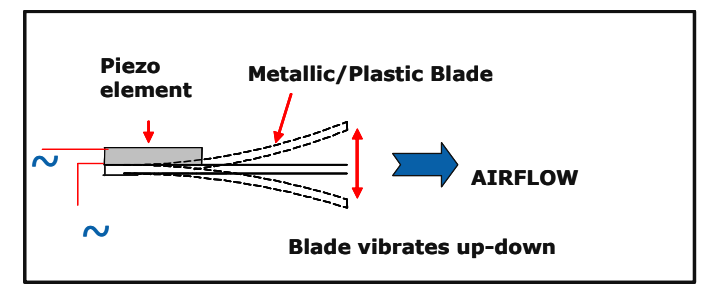

Fig. 15 Basic principle of piezo fan

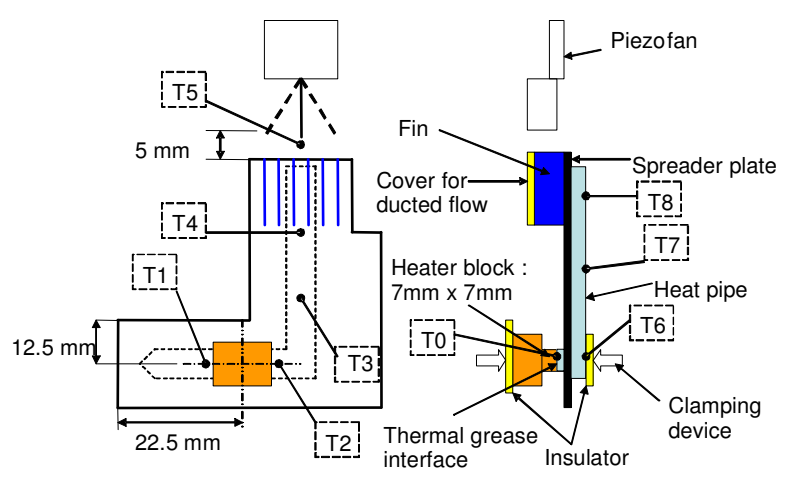

Fig. 16 Thermal solution consist of heat pipes with spreader plate and piezo fan

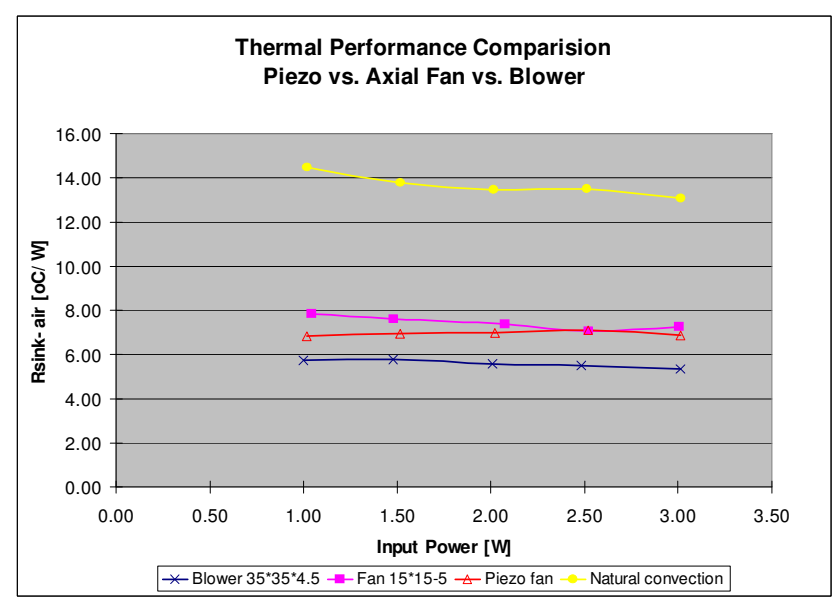

Fig. 17 Thermal performance comparison between piezo fan, axial fan and air blower

Figure 16 shows the concept of using piezo fan with heat spreader plate and heat pipe. Piezo fan, axial DC fan and DC blower were tested on the same thermal module for thermal comparison. Thermal test results shown in Fig. 17 indicated that piezo fan performed similar with traditional rotational fans. The main advantages of piezo fan is low acoustic and low cost.

Figure 18 shows a novel multiple piezo fan design, so called "raked" piezo. In this type of design, in addition to the air flow generation, the blades thinning or destructing the thermal boundary layer proximity to the heat sink fin surfaces and blades. This would improve the heat transfer coefficient, and therefore would provide better cooling. The thermal performance of this concept could significantly improved by $40 \%$ as shown in Fig. 19. The inclination angle of piezo fan with respect to the heat sink can affect the performance, and in this particular case the inclination angle is 75 degrees. Further study is needed for different geometries of heat sink and piezo fan in order to make more comprehensive conclusion.

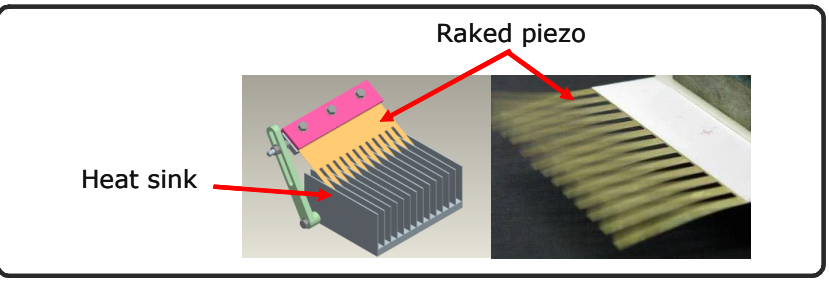

Fig. 18 Raked piezo fan

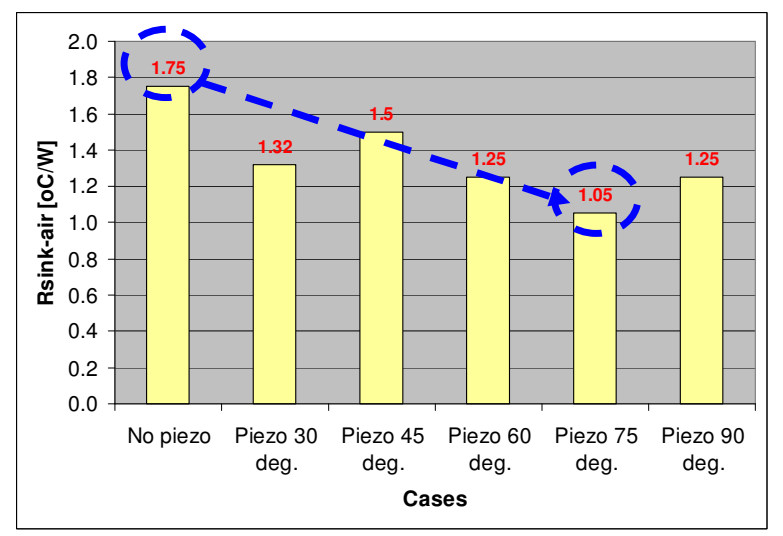

Fig. 19 Thermal performance of raked piezo fan 


\section{FUTURE TECHNOLOGIES}

\subsection{Improve heat spreading from the processor die}

As shown previously in Fig. 3(a) is a schematic presentation of the thermal resistance network. In the current technology, the IHS is made of solid $\mathrm{Cu}$ plate which interfaced with CPU's die via thermal grease. The average thermal spreading resistance between the die and the IHS $\left(\mathrm{R}_{\mathrm{jc}}\right.$ in Fig. $\left.3 \mathrm{~b}\right)$ is a significant ratio to overall thermal resistance.

There are some possibilities to improve the thermal spreading resistance between CPU's die and the IHS as described in the following sections.

- Instead of solid $\mathrm{Cu}$ metal IHS, use a two-phase micro-channel vapor chamber (MVC) as shown in Fig. 20. Basically, the MVC is an evacuated and a sealed container that contains a small quantity of working fluid. Inside the container has skive micro-fin structures that increases the boiling heat transfer area. When one side of the container is heated, it causes the liquid to vaporize and the vapor to move to the cold side and condense. As the latent heat of evaporation is large, considerable quantities of heat can be transported with a very small temperature difference from end to end. Therefore, the MVC-IHS has low spreading thermal resistance, isothermal temperature distribution, and no local hot spot compared with solid $\mathrm{Cu}$ IHS where heat spread solely by thermal conduction.

- Instead of using thermal grease between CPU's die and IHS, the use of brazing or soldering to minimize the contact resistance should be considered. There would be technical challenges such as thermal expansion coefficient mismatch between mating surfaces; reliability issues such as corrosion, chemical reaction and so on. It is possible that the surface could be plated with materials having similar thermal expansion coefficient and corrosion resistance.
- Current solid metal IHS

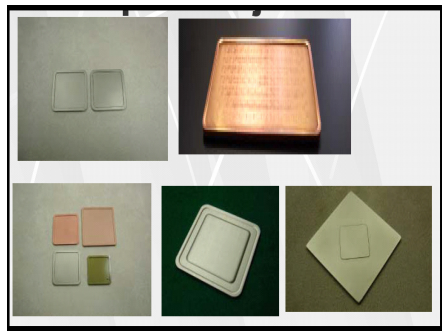

- Proposed MVC IHS

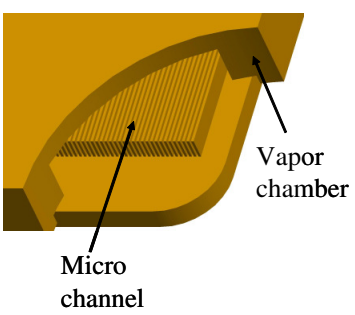

Fig. 20 Micro-channel vapor chamber

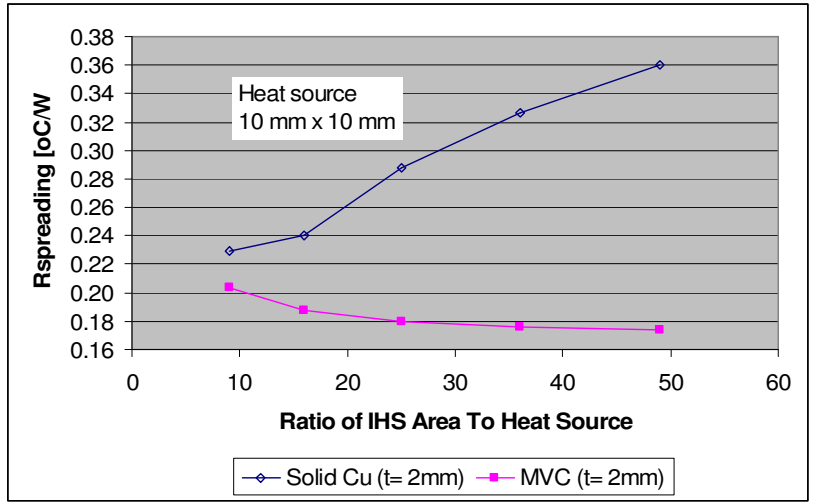

Fig. 21 Thermal spreading resistance comparison between $\mathrm{Cu}-\mathrm{IHS}$ and MVC-IHS
Figure 21 shows an estimate calculation of thermal spreading resistance and comparison between solid $\mathrm{Cu}-\mathrm{IHS}$ and MVC-IHS for various IHS sizes. The use of MVC-IHS is an advantage when the IHS size is about 10 times of the die size based on the assumption that the die size is $10 \mathrm{~mm} \times 10 \mathrm{~mm}$.

Figure 22 shows a photo of the skive micro-fin structure. The manufacturing technique is slicing a block of metal to make the fins. The manufacturing capability are as shown below :

- $\quad$ Minimum fin thickness $50 \mathrm{um}$.

Minimum fin pitch $100 \mathrm{um}$.

Maximum fin height $5000 \mathrm{um}$.

Minimum base thickness $300 \mathrm{um}$.

The advantages of the skive micro-fin are that a significant increase in fin surface areas available for heat transfer due to the fine fin thickness and pitch. The fins and base is made from a solid piece of metal, therefore no fin to base thermal contact resistance.

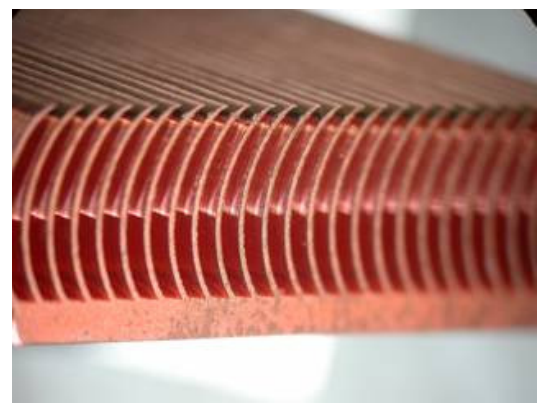

Fig. 22 Skive micro-fin structure

\subsection{Remove integrated heat spreader (IHS)}

As mentioned before, the average thermal spreading resistance between the die and the IHS ( $\mathrm{R}_{\mathrm{jc}}$ in Fig. $3 b$ ) is a significant ratio to overall thermal resistance, therefore remove the IHS could improve overall thermal performance. The concept of no IHS cooling module is shown in Fig. 23. In the current, most of the notebook use bare die (no IHS), but for desktop and server processors still IHS present. The reason is likely due to reliability issue because usually the cooling module for desktop and server are large and heavy compared to notebook cooling module. Large and heavy cooling module would exert higher stress on the processor's die and may cause crack and fatigue failure.

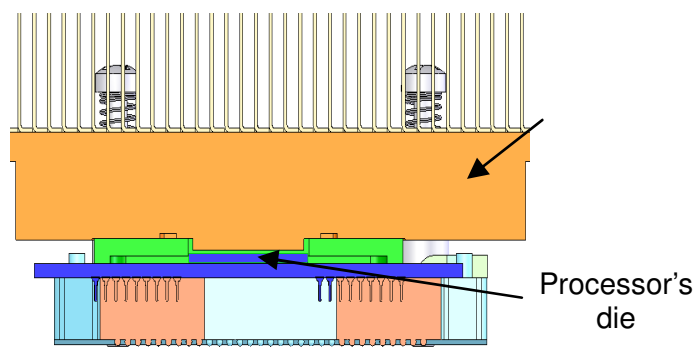

Fig. 23 Thermal solution without IHS

\subsection{Heat pipe improvement}

As have been mentioned earlier, the processor's die surface, where the heat is generated, is usually small, approximately $1 \mathrm{~cm}^{2}$, so for effective cooling least temperature gradient between the heat source and radiating components should be required. The best-known devices for effective heat transfer with lowest thermal resistance are the heat pipes and vapor chambers. As the power and heat flux of the processor continues rising, it is most vital to improve the heat pipe maximum heat transfer $\left(\mathrm{Q}_{\max }\right)$ and reduce heat pipe thermal resistance $\left(\mathrm{R}_{\mathrm{hp}}\right)$. There are 
some possibilities for the heat pipe improvement as described in the following sections.

- New sintered powder wick heat pipe: The size of powder particles and porosity are the main factors in optimizing maximum capillary forces while there is a need to maintain high permeability. Besides wick thickness and uniformity are key factors for better and stable heat pipe performance.

- New working fluid to improve fluid-wick wet-ability and boiling heat transfer. Preliminary study showed that dilute aqueous solutions of high-carbon alcohols that presented a particular surface tension behavior that have strong liquid flow in the nucleation sites during the boiling process. Experimental studies showed that in pool boiling heat transfer, a significantly smaller bubble size is formed in comparison with water. This indicated that the heat transfer performance would be improved. Figure 24 shows a significant improvement in maximum heat transfer for $1.5 \mathrm{~mm}$ flatten heat pipe. Results showed heat transfer increased from 8 to $34 \mathrm{~W}$.

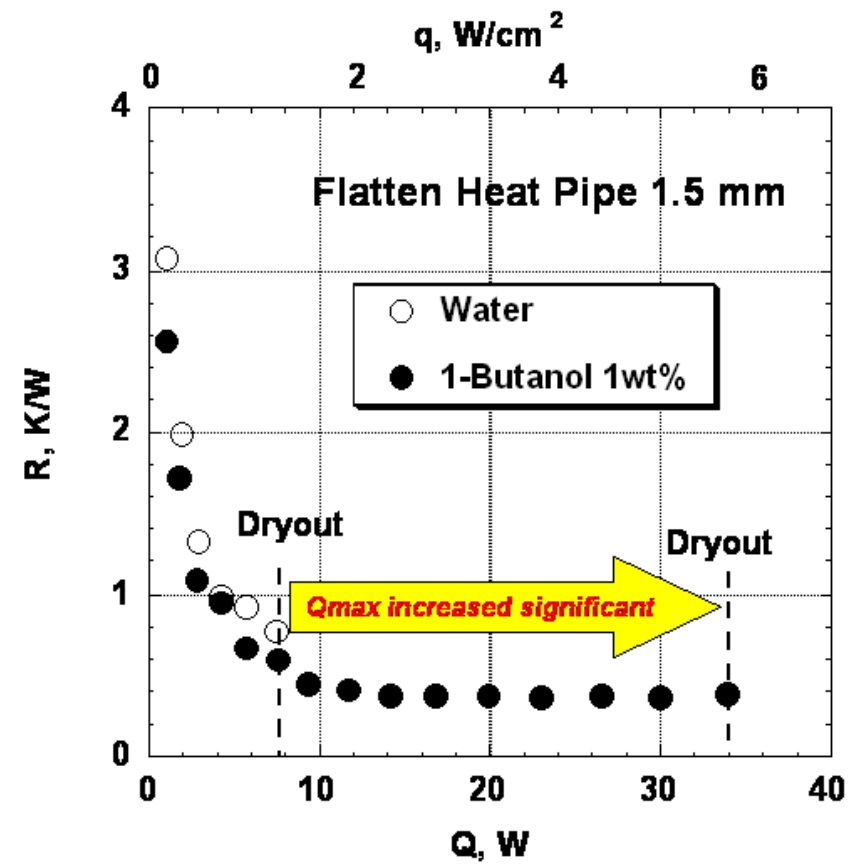

Fig. 24 Heat pipe performance comparison of different fluids

\subsection{Vapor chamber improvement}

Figure 25 shows various ideas how to improve the heat transfer performance in vapor chamber. Increase permeability by adding grooves for liquid to flow easily. Additional screen mesh will increase the capillary force.

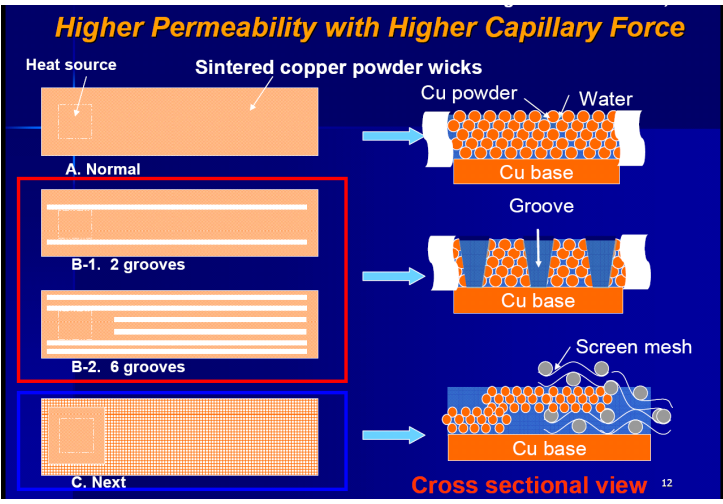

Fig. 25 Vapor chamber improvement ideas
Figure 26 shows results for the same vapor chamber configuration, the heat transfer increased from 72 to about $87 \mathrm{~W}$.

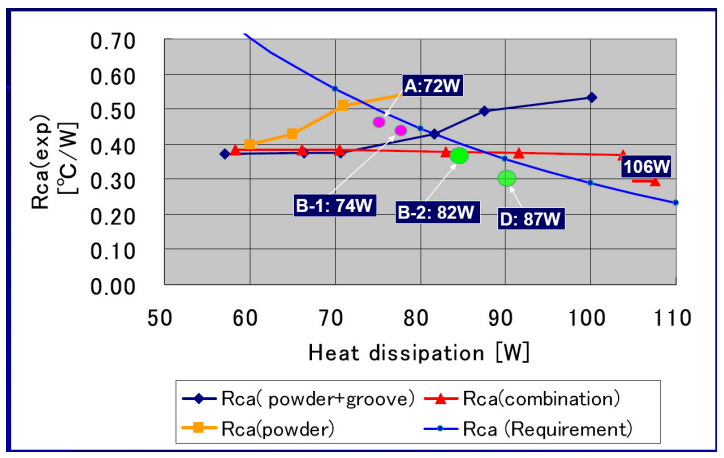

Fig. 26 Vapor chamber performance improvement

\subsection{Micro-channel two-phase pump loop}

Figure 27 shows a schematic of the micro-channel two-phase pump loop. Detail information of the system will not be given here, except the concept. Typical results indicated that this system could achieve the evaporator thermal impedance less than $0.1{ }^{\circ} \mathrm{C}-\mathrm{cm}^{2} / \mathrm{W}$ at saturated water flow rate less than $50 \mathrm{ml} / \mathrm{min}$. The system is capable heat flux greater than $50 \mathrm{~W} / \mathrm{cm}^{2}$.

Other possibility to improve vapor chamber performance is to consider higher thermal conductivity material than copper of the vapor chamber base. For example, the vapor chamber base could be plated with higher thermal conductivity material such as graphite or diamond. Higher thermal conductivity of the base will help to increase spreading heat transfer, and thus increase the evaporation surface area.

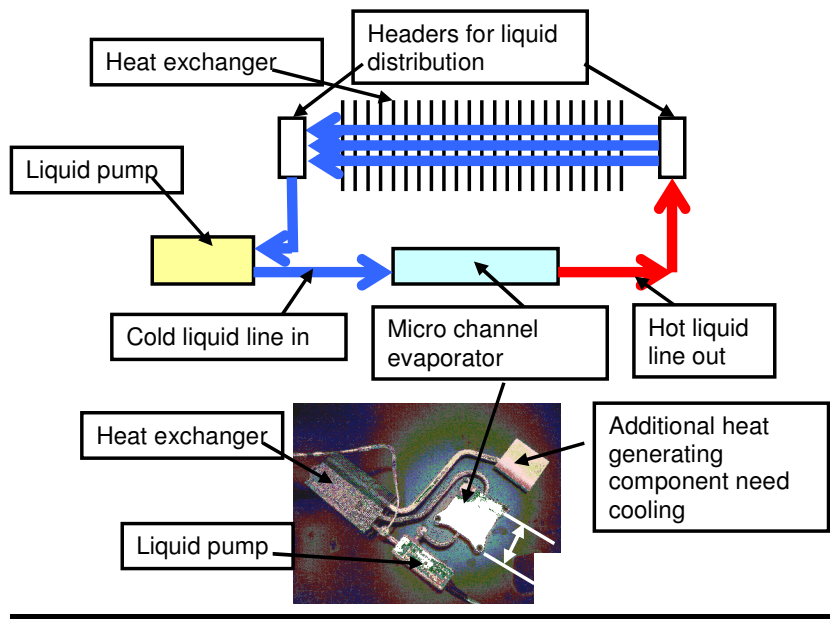

Fig. 27 Schematic micro-channel two-phase pump loop

\section{RENEWABLE ENERGIES}

\subsection{Case study 1 - A heat pipe cold storage system for cooling data centers}

As described in the introduction, a major operational cost of data centers is electric power consumption, and as the power supplied to the data center processing units is ultimately dissipated as heat, a significant fraction of data center power is used to cool these units (Brill, 2010; Schmidt et al., 2005). As shown in Fig. 28, their power consumption is estimated to double every 5 years. The power consumption of data centers in 2001 was about $30 \times 10^{9} \mathrm{kWh}$, and is expected to increase to $120 \times 10^{9} \mathrm{kWh}$ in 2011. This is equivalent to about 13.2 million houses of electric power consumption. 
Figure 29 shows a typical example of the current practice hot cold air flow heat exchange for thermal management of data centers. The authors propose a system which utilizes the thermosiphon to capture and store cold energy from the ambient to the storage media. The cold energy can be used for cooling of the data center. The concept schematic is shown in Fig. 30. This system can reduce electrical power consumption related to cooling data centers. The entire system needs to be installed in cold regions at an underground level.

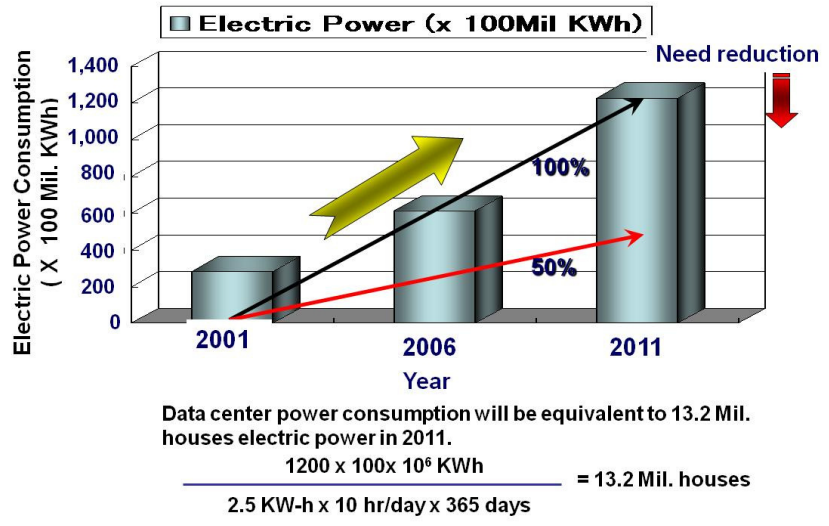

Fig. 28 Power consumption in data centers

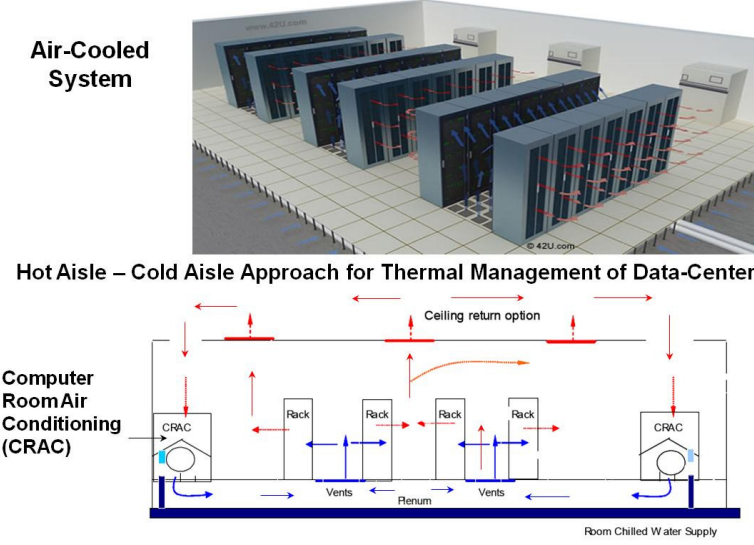

Fig. 29 Typical example of current thermal management system in data centers

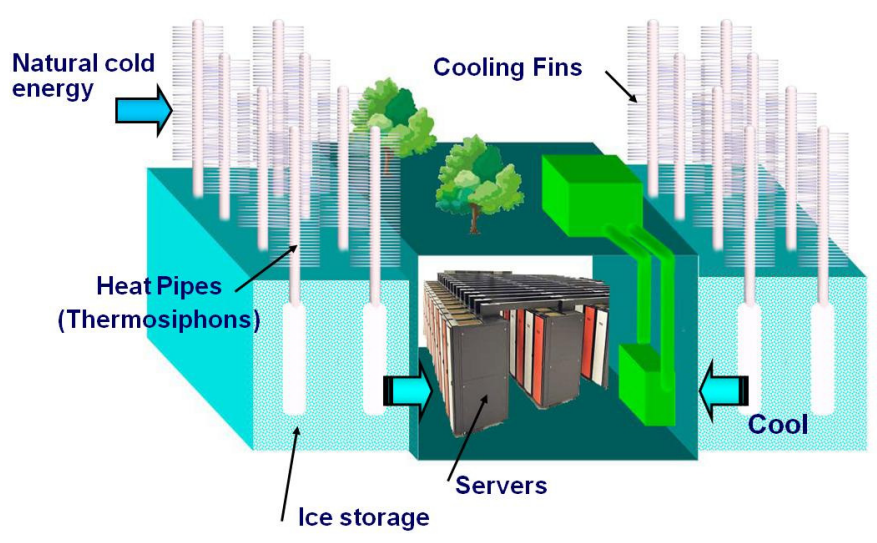

Fig. 30 Concept of cold energy storage for cooling data centers

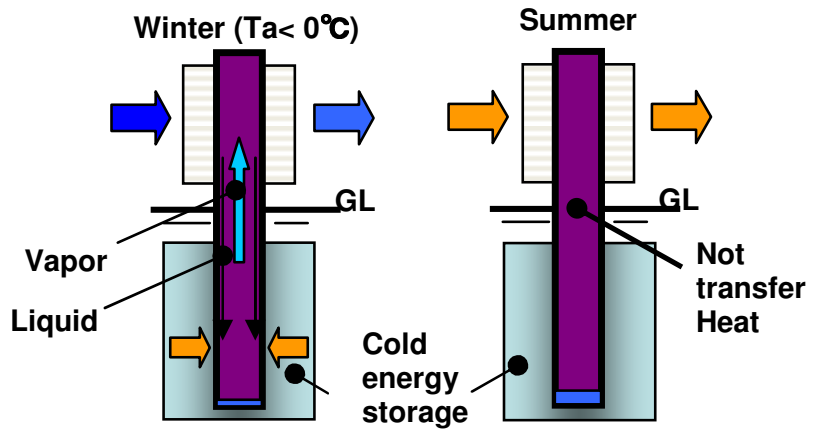

Heat pipe works
(bottom heat mode)

Heat pipe does not work. (top heat mode)

Fig. 31 Thermosiphon diode characteristics

\section{1(a) An Ice Storage System for Support of Main Cooling System Failure}

Figure 32 shows another concept that uses an ice storage system to support failure or shut down of the main cooling system. Based on the American Society of Heating, Refrigerating, Air-Conditioning Engineers Standard, the requirement for failure support time is $6 \mathrm{~h}$, therefore, for an $8800 \mathrm{~kW}$ data center, the heat output required is approximate $53 \mathrm{MWh}$. The ice storage system needs to support cooling only during times of failure.

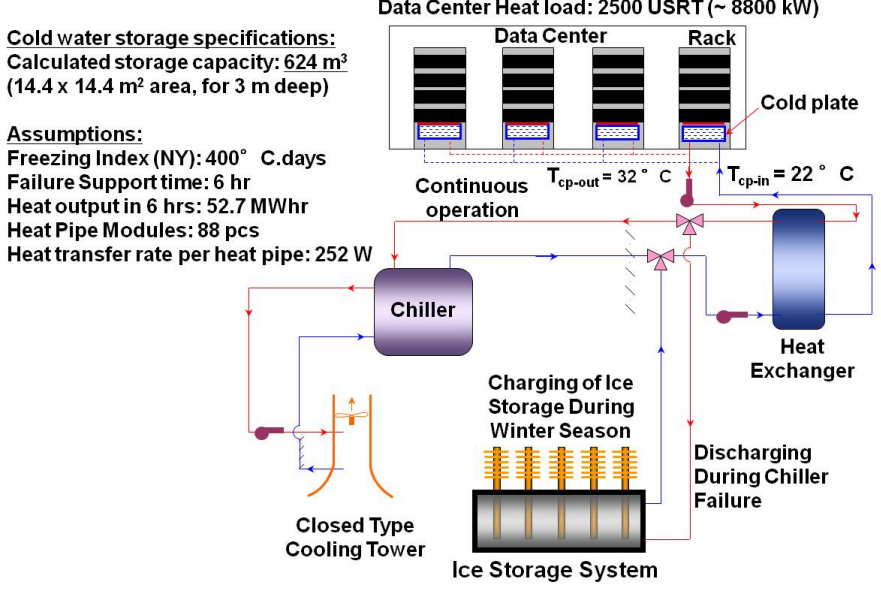

Fig. 32 Ice storage system to support data center failure time

Figure 33 shows structural comparison of the current cold water system and the proposed ice storage system. The current system uses a cold water storage tank in which the water temperature is maintained by a chiller. The proposed ice storage system uses thermosiphons to collect and store ambient cold energy for cooling the data center when the main cooling system shuts down. The advantages of the ice storage system to the current cold water system are shown in Table 1 . Calculation results show that the ice storage occupies $86 \%$ less space, consumes no electric power, causes no $\mathrm{CO}_{2}$ emission, and requires minimal cost compared to the current cold water system.

\section{1(b) Pre Cooler for Chiller Inlet Water}

Another concept for energy conservation is to use a thermosiphon heat exchanger to pre-cool the hot water inlet of the chiller (vapor compression refrigerator), thereby reducing chiller runtime and electricity costs. The system is shown in Fig. 34. The pre-cooler was designed to reduce the water inlet temperature of the chiller from 25 to $20{ }^{\circ} \mathrm{C}$. The design is based on the weather conditions shown in Fig. 35 for Poughkeepsie, New York, in the USA. 


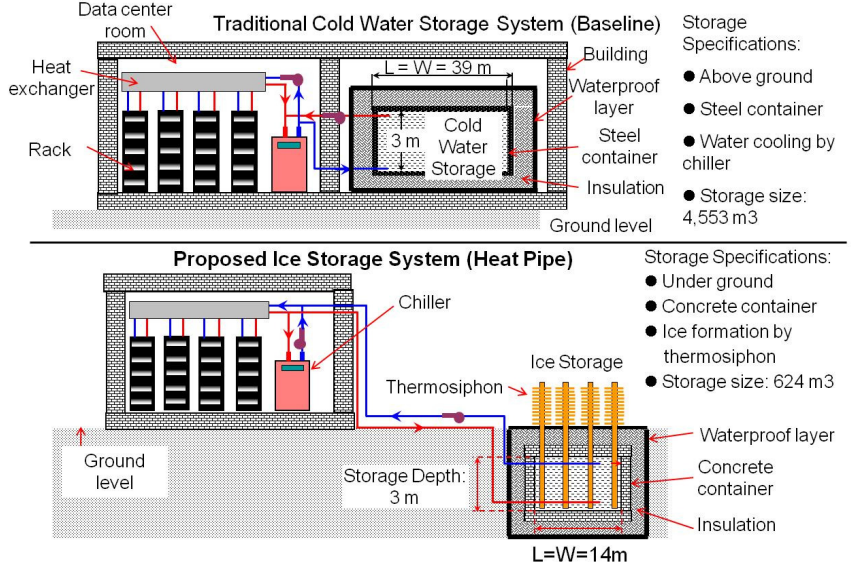

Fig. 33 Structure comparison between current system (top) and the proposed ice storage system (bottom)

Table 1 Advantages between the current system and proposed ice storage system

\begin{tabular}{|l|c|c|}
\hline Sizes & $\begin{array}{c}\text { Current System } \\
\text { Cold Water Storage }\end{array}$ & $\begin{array}{c}\text { Proposed System } \\
\text { Ice Storage }\end{array}$ \\
\hline Energy Storage & $\begin{array}{c}\sim 4,600 \mathrm{~m} 3 \\
(39 \mathrm{~m} \times 39 \mathrm{~m} \times 3 \mathrm{~m} \text { deep })\end{array}$ & $\begin{array}{c}\sim 650 \mathrm{~m} 3(14 \%) \\
(14.4 \mathrm{~m} \times 14.4 \mathrm{~m} \times 3 \mathrm{~m} \text { deep })\end{array}$ \\
\hline Construction & Same & $\begin{array}{c}\sim 63 \mathrm{MWhr} \\
(6 \mathrm{hrs} \text { cooling })\end{array}$ \\
\hline Heat Pipes & $\begin{array}{c}\text { Steel } \\
\text { (Above ground) }\end{array}$ & $\begin{array}{c}\text { Concrete } \\
\text { (Below ground) }\end{array}$ \\
\hline Power consumption & None & 88 heat pipe modules \\
\hline $\mathrm{CO}_{2}$ Emission & Running Chiller & None \\
$\mathrm{Cost}$ & 13 tons (6hrs operating) \\
$\sim 5 \$$ Mil & None \\
\hline
\end{tabular}

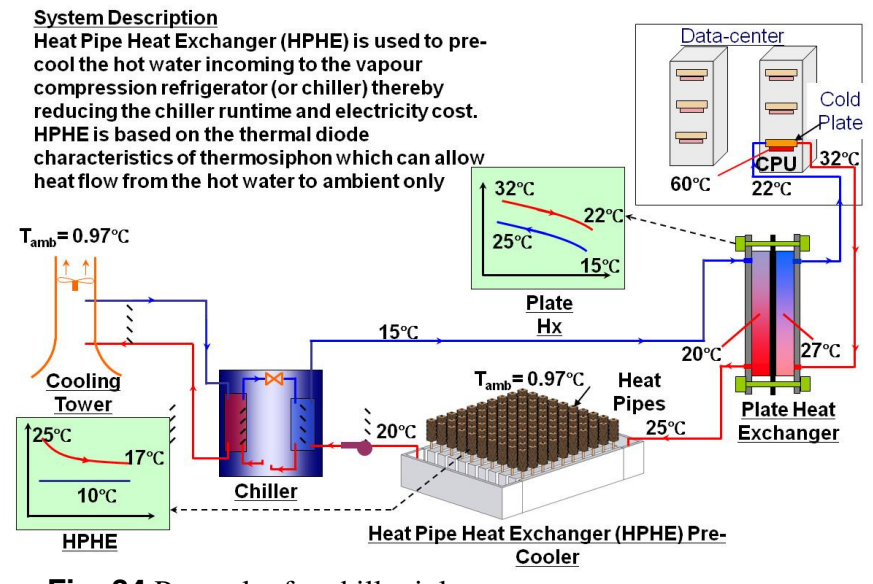

Fig. 34 Precooler for chiller inlet water

Figure 36 shows a design of the pre cooler for an $8800 \mathrm{~kW}$ data center. It consists of 2160 thermosiphon modules placed in a water chamber of sizes approximately $60 \mathrm{~m}$ in length, $40 \mathrm{~m}$ in width, and 3.5 $\mathrm{m}$ in height. Each thermosiphon has dimensions of $50.8 \mathrm{~mm}$ outer diameter and $7 \mathrm{~m}$ total length. The $3 \mathrm{~m}$ length of the evaporator is submersed in the water cooler chamber, and the $3 \mathrm{~m}$ length of the condenser is exposed to ambient for cooling. The condenser has 300 pieces of aluminum fins of length $300 \mathrm{~mm}$, width $300 \mathrm{~mm}$, and $1 \mathrm{~mm}$ thickness.

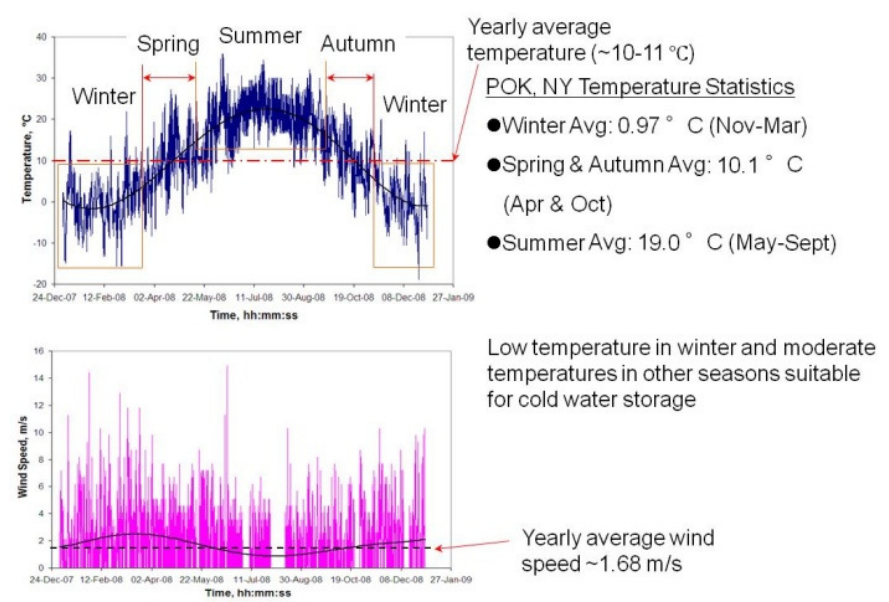

Fig. 35 Hourly temperature and wind speed for Poughkeepsie, New York, USA, 2008

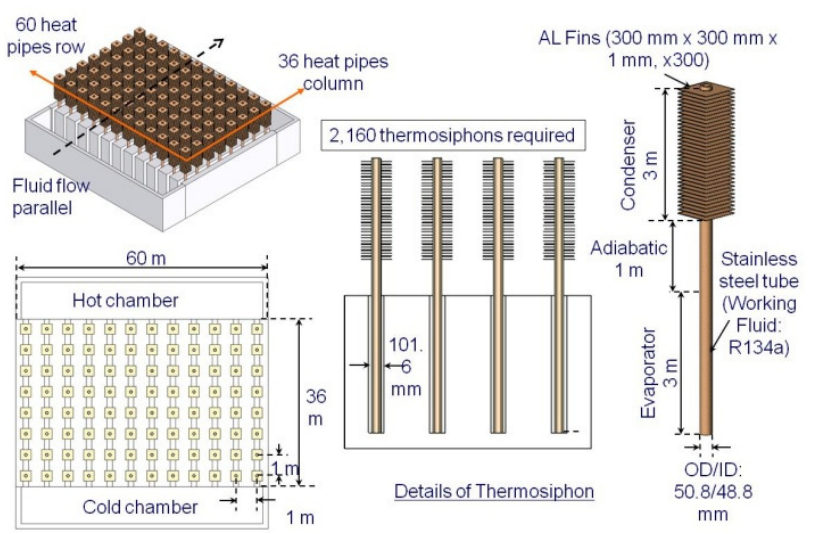

Fig. 36 Pre cooler design for $8800 \mathrm{~kW}$ data center

Table 2 shows some key highlights of the pre cooler for two cases, an $8800 \mathrm{~kW}$ and $1060 \mathrm{~kW}$ data center. The highest cooling capacity is in winter, where $50 \%$ of the data center cooling is from the pre-cooler, $30 \%$ in autumn and spring, and the lowest cooling capability of $12.5 \%$ is in summer. The payback time for the pre cooler is less than 2 years.

Table 2 Pre cooler highlights

\begin{tabular}{|c|c|c|}
\hline & $\begin{array}{l}2,500 \text { USRT Data Center } \\
(\sim 8,800 \mathrm{~kW})\end{array}$ & $\begin{array}{l}300 \text { USRT Data Center } \\
(\sim 1,060 \mathrm{~kW}) \quad 12 \%\end{array}$ \\
\hline $\begin{array}{l}\text { Sizes of Heat } \\
\text { Exchanger }\end{array}$ & $\mathrm{L} 60 \mathrm{~m} \times \mathrm{W} 40 \mathrm{~m} \times \mathrm{H} 7 \mathrm{~m}$ & $\mathrm{~L} 20 \mathrm{~m} \times \mathrm{W} 15 \mathrm{~m} \times \mathrm{H} 7 \mathrm{~m}$ \\
\hline Cooling Capability & $\begin{array}{l}\text { Winter : } 4,400 \mathrm{~kW} \\
\text { Autum/Spring : } 2,700 \mathrm{~kW} \\
\text { Summer : } 1,100 \mathrm{~kW}\end{array}$ & $\begin{array}{c}\text { Winter : } 530 \mathrm{~kW} \\
\text { Autum/Spring: } 320 \mathrm{~kW} \\
\text { Summer: } 130 \mathrm{~kW}\end{array}$ \\
\hline Heat Pipes Modules & 2,160 & 260 \\
\hline Cost Savings / Year & $\sim 0.6 \$$ Mil & $\sim 72 \$ \mathrm{~K}$ \\
\hline Initial Cost & $\sim 1.14$ \$Mil & $\sim 130$ \$K \\
\hline Pay back & $<2$ years & $<2$ years \\
\hline
\end{tabular}

\section{1(c) Experimental Study - Proof of Concept}

Figure 37 shows the test set up and the experimental facility where the module was tested. A thermosiphon is made of stainless steel, and R134a was used as the working fluid. To minimize heat leaks from the 
ambient, the evaporator section of the thermosiphon and the storage tank were buried under ground, and the outer surface of the tank was properly insulated. This helps to avoid heat gain from the ground and ambient during the summer season.

Figure 38 shows the preliminary test results. The experiment was initially carried out for 25 days and within this period, approximately $113 \mathrm{~kg}$ of ice was formed which was estimated visually by opening the tank and confirmed by the readings of the thermocouples installed inside the tank (T1-T4). Experimental results were compared with the predicted ice formation tendency of the heat pipe module using an analytical model that showed good agreement and therefore helped to validate the model.
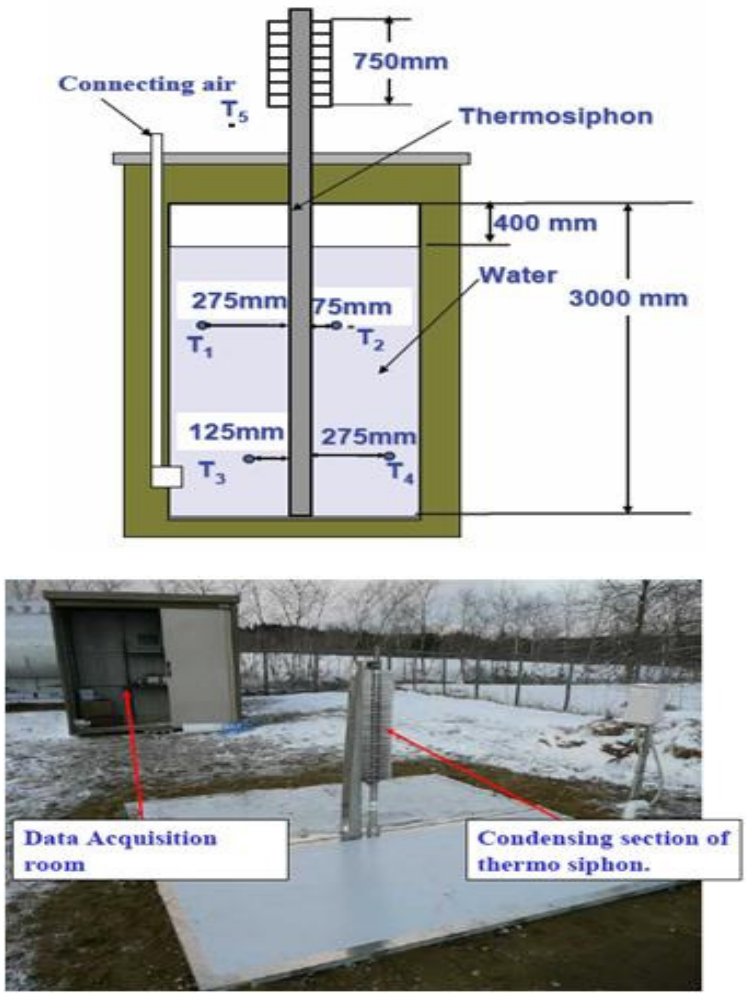

Fig. 37 Pre cooler design for $8800 \mathrm{~kW}$ data center

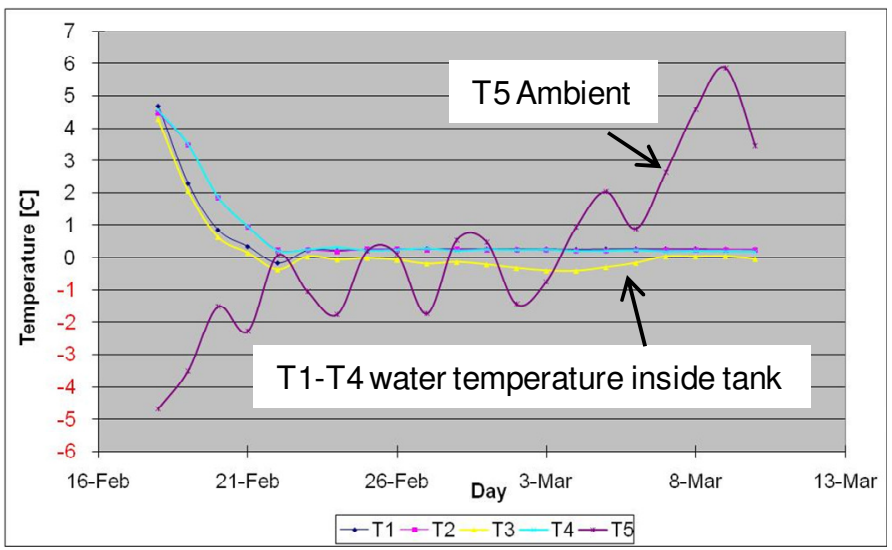

Fig. 38 Experimental test results of ice formation

Heat transfer from the thermosiphon to the water storage decreased due to the formation of ice on the evaporator surface of the thermosiphon. The thicker the ice, the lower the heat transfer from the thermosiphon to water, because ice has poor thermal conductivity. To minimize this problem it is possible to apply high-frequency alternate current to the surface of the evaporator in short time to break up the ice formation. This concept is shown in Fig. 39.
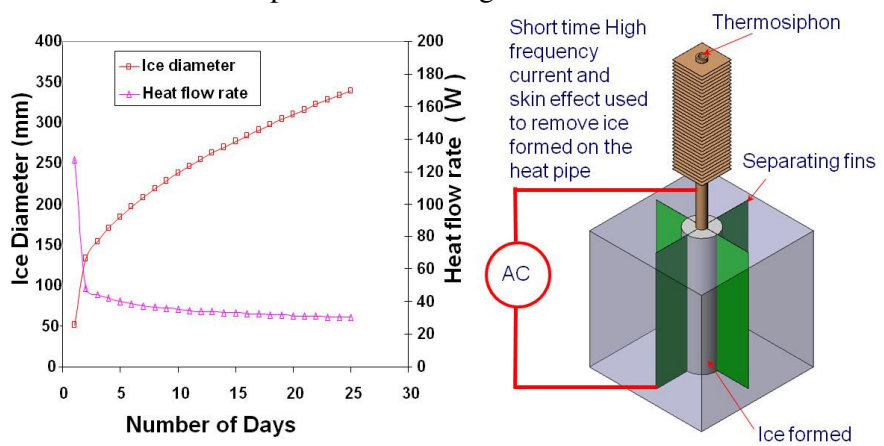

Fig. 39 Concept of ice removal on the surface of the evaporator

\subsection{Case study 2 - Cold energy storage for agricultural products}

Figure 40 shows the concept of using a heat pipe to collect cold energy in the winter season and storing underground to create a permafrost system for storage of agricultural products throughout the year. The prototype shown was built in Hokkaido of Japan, where the freezing index is above $400^{\circ} \mathrm{C}$ per day. The freezing index is defined as the product of number of days in a year and the average ambient temperature below zero degrees Celsius. Figure 41 shows the freezing indexes for some countries. There are 216 stainless steel heat pipes of $46 \mathrm{~mm}$ diameter and $12 \mathrm{~m}$ length installed around the store room at 0.5 $\mathrm{m}$ intervals. The store room was $6 \mathrm{~m}$ long $\mathrm{x} 3.6 \mathrm{~m}$ wide $\mathrm{x} 3.6 \mathrm{~m}$ high. The heat pipe evaporator is buried in the soil, and the condenser is exposed and cooled by natural ambient. In the winter season, the cold energy system can make a 2-m-thick layer of frozen soil and keep the store room below $4^{\circ} \mathrm{C}$. The humidity was above $85 \%$ throughout the summer. The whole cold energy system is passive, ie., there are no moving parts, there is no electrical consumption, and it is reliable and maintenance free.

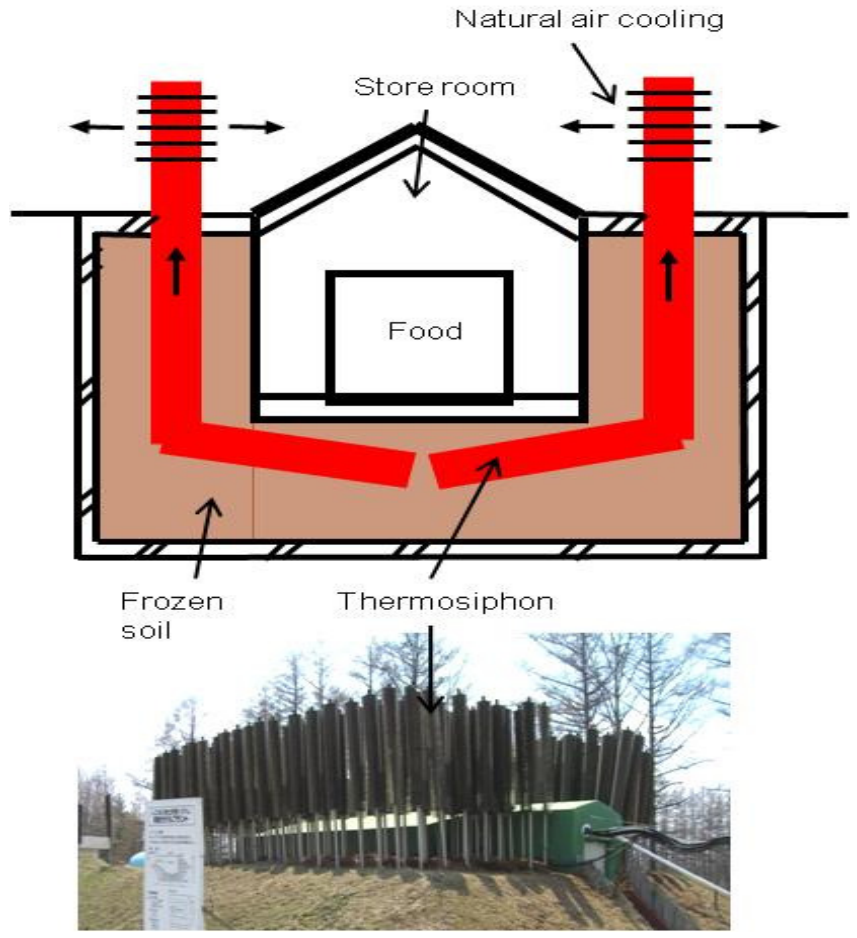

Fig. 40 Permafrost storage system 


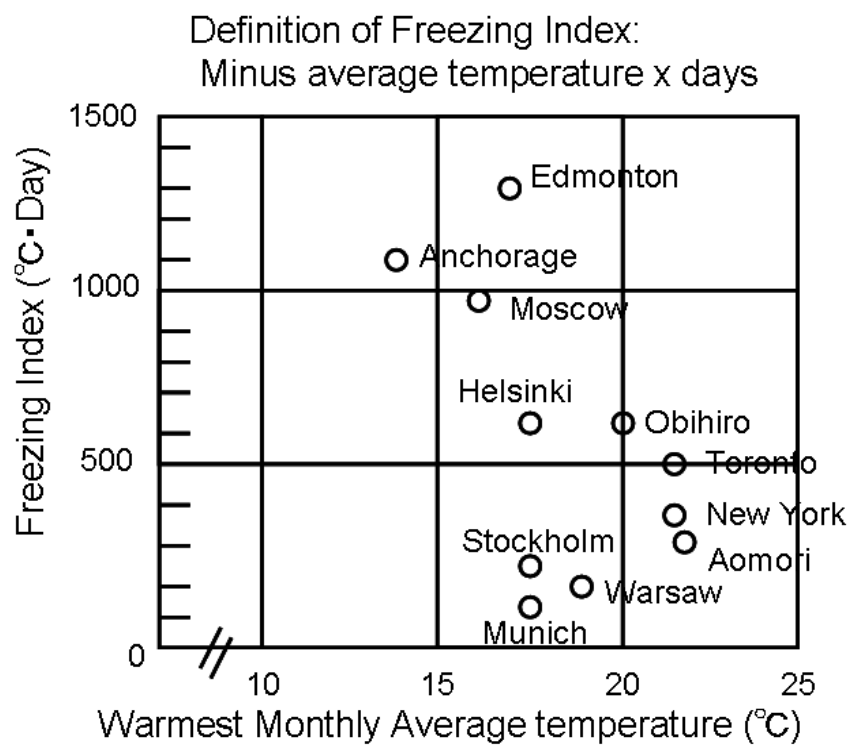

Fig. 41 Freezing index

The authors believe that this system is an attractive of helping save the earth from global warming. It is applicable in cold regions where the freezing index is at least $400^{\circ} \mathrm{C}$ per day, making it economically viable.

\subsection{Case study 3 - Heat pipe and phase change material for cooling concentrated photovoltaic technology}

Concentrated photo-voltaic (CPV) technology offers incentives in terms of high conversion efficiency, semiconductor material savings and low unit electricity cost $(\$ / \mathrm{W})$ as compared to flat-plate photo-voltaic modules. Thermal control of photo-voltaic cells is necessary to reduce temperature-related performance or efficiency drop and avoid material degradation. A $1^{\circ} \mathrm{C}$ cooling of photo-voltaic can help increase energy conversion efficiency in general by $0.5 \%$. This section outlines the concepts of cooling solar CPV modules by means such as heat transport from cells to remote heat sinks by passive thermosiphons or active mechanical pumps, and diurnal storage of waste heat output by cells during the daytime in low-temperature phase change materials (PCMs) and night-time heat dissipation to ambient by means of natural convection and night sky radiation. Figure 42 shows the concept of cooling the solar CPV module. The PV cells are attached to the bottom side of the evaporator of the thermosiphon which is located at the focus line above the parabolic trough. The PV cells are used to collect the concentrated solar radiation reflected from the parabolic trough and convert the solar radiation into electricity. The PV cells must be cooled for it to operate, and this is done by use of the thermosiphon to extract the heat from the PV cells and cooling in ambient using fin heat exchangers. Figure 43 shows another concept of cooling solar CPV modules by use of PCMs. The heat produced from the PV cells during the daytime is stored in the PCM, which is then cooled at night by night sky radiation and natural convection cooling. The PCM is a lowtemperature organic phase change material Polyethylene Glycol (PEG), which has a melting temperature of less than $40^{\circ} \mathrm{C}$. In this concept a pump is required to pump the water to cool the PV cells, and the heated water is cooled by the PCM. In the PCM module there are heat pipes installed laterally to improve the heat transfer within the PCM, because the thermal conductivity of the PCM is low, about $0.2 \mathrm{~W} / \mathrm{m} . \mathrm{K}$.

Figure 44 shows the relationship between the clear sky temperature and the ambient temperature. This strongly shows the prospective low sky temperature available for radiation cooling. For example, at $15^{\circ} \mathrm{C}$ ambient temperature and $50 \%$ humidity the sky temperature is $0^{\circ} \mathrm{C}$.

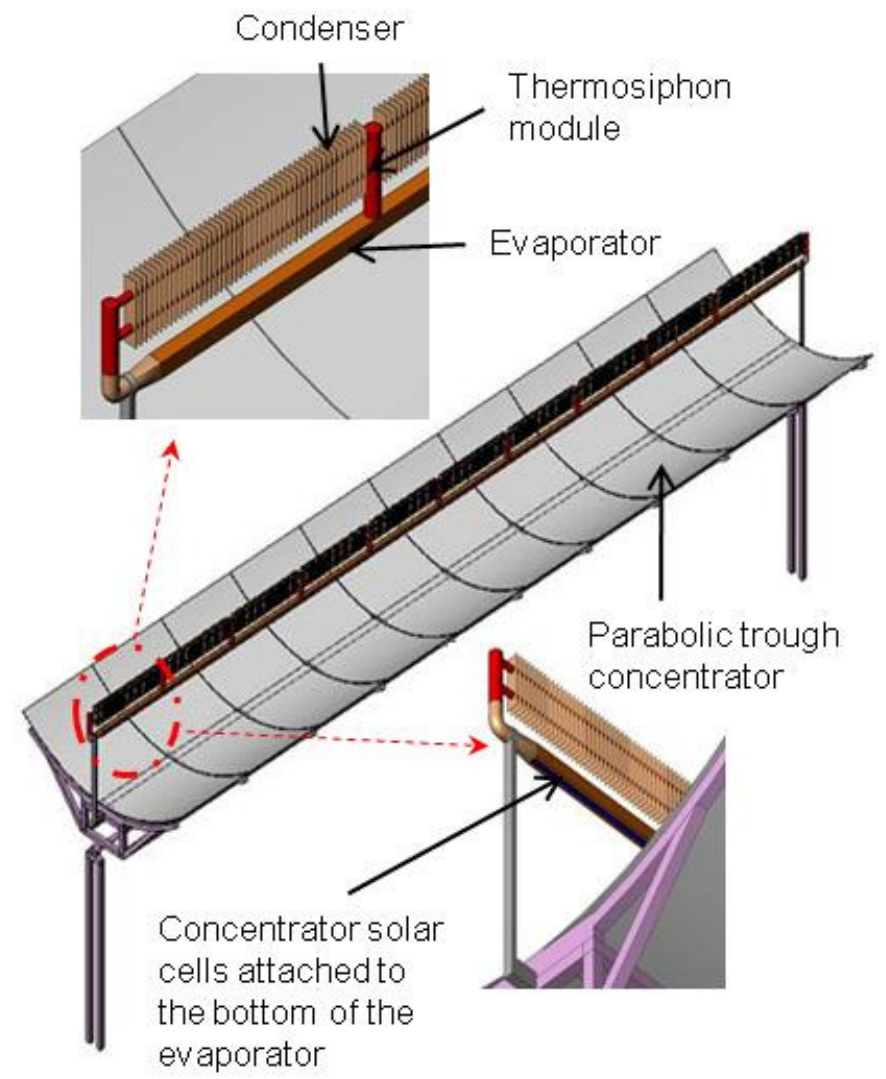

Fig. 42 CPV Cooling by thermosiphons with fin heat exchangers

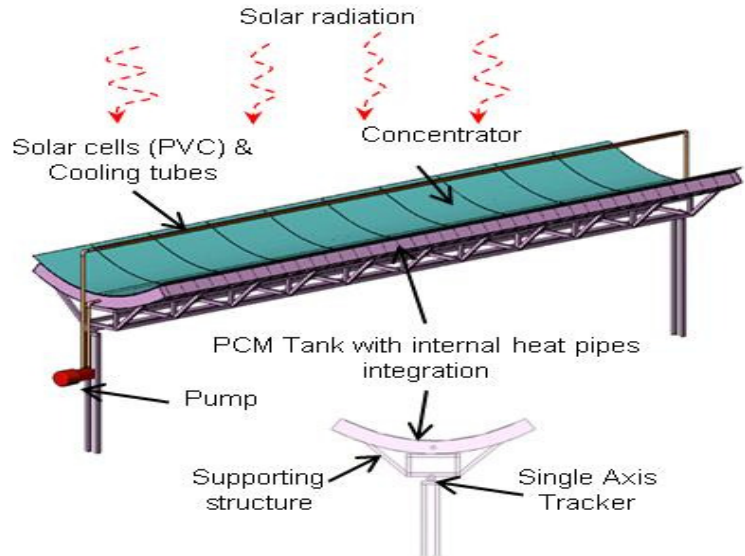

(a) Solar radiation day time

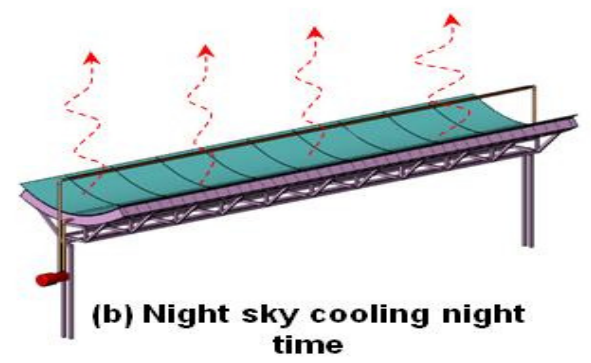

Fig. 43 CPV cooling by use of PCM and night-time sky radiation 


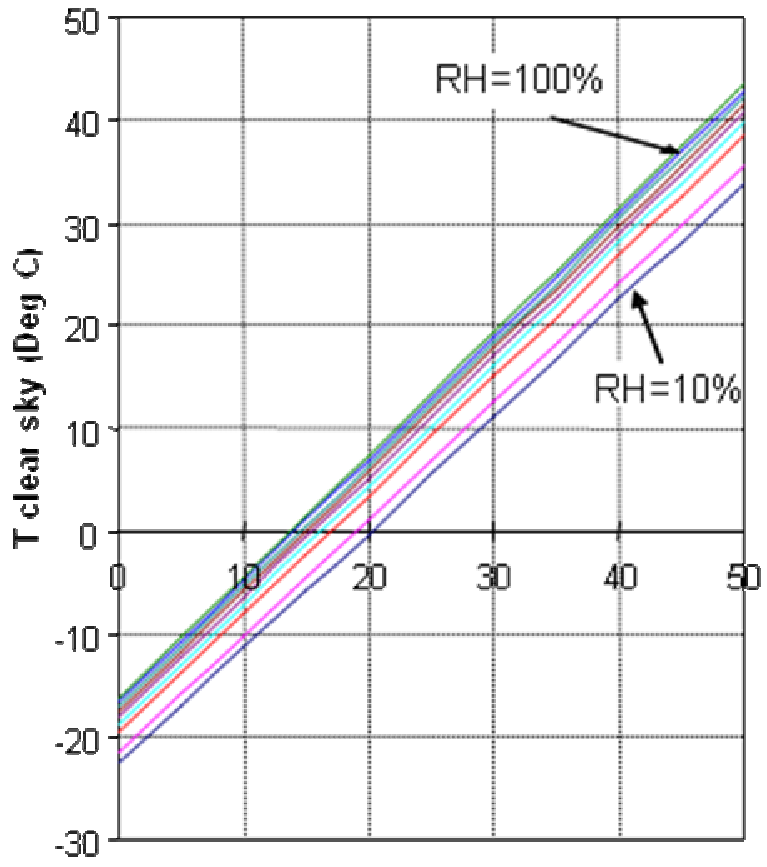

Tambient (Dey C)

Fig. 44 Sky temperature vs ambient temperature

\subsection{Case study 4 - Large scale loop heat pipe for geothermal heat extraction}

Figure 45 shows the concept of using large heat pipes for extraction of geothermal heat. Conventional heat pipes will not work by simply enlarging the heat pipe diameter and length, because the heat load will cause entrainment and flooding phenomena within the heat pipe. With a long heat pipe heat-transfer performance will deteriorate as well due to the difficulty of maintaining uniform liquid film throughout the length of the heat pipe. To address these issues a new concept in heat pipes was developed in which the flow of vapor and liquid are separated. As shown in Fig. 45, the liquid flow is separated from the vapor flow. The liquid is fed through a feed tube having a number of nozzles to spray the liquid onto the inner surface of the evaporator of the heat pipe. The spraying of liquid on the evaporator enhances the evaporation heat transfer of the heat pipe. A prototype of this $150 \mathrm{~mm}$ diam x $150 \mathrm{~m}$ long loop-type heat pipe water as working fluid, was developed and installed in Kyushu Island of Japan.

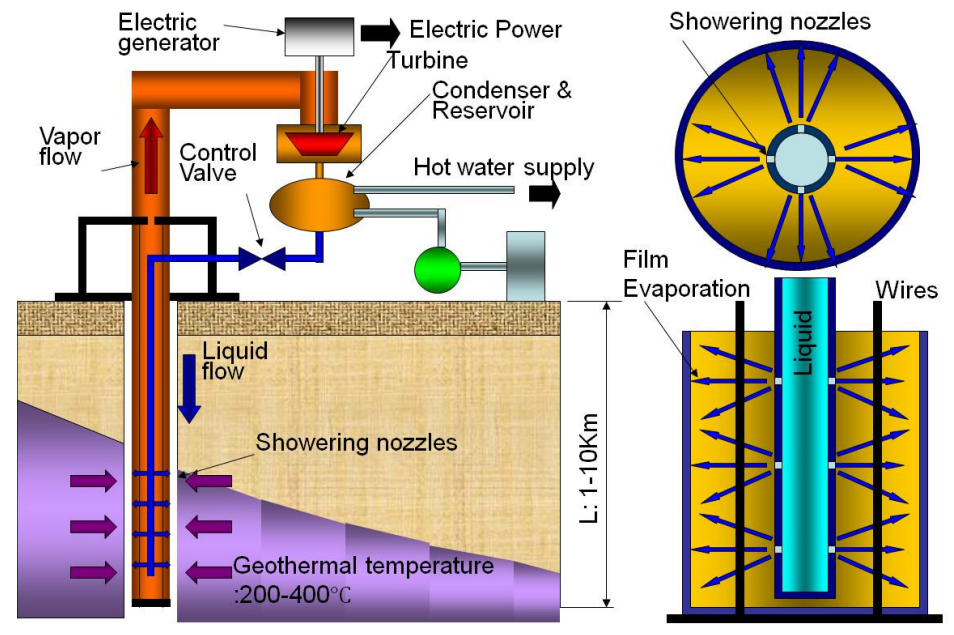

Fig. 45 Large scale heat pipe for geothermal extraction heat
Experimental results are shown in Fig. 46. The results showed 65 $\mathrm{kW}$ of heat can be extracted at a flow rate of $1.2 \mathrm{~L} / \mathrm{m}$ and at working temperature of approx. $70{ }^{\circ} \mathrm{C}$. It is estimated that over $100 \mathrm{~kW}$ can be obtained at a working temperature of $100^{\circ} \mathrm{C}$. Refer to Ref. (Mashiko et al., 1994) for detailed analysis of the prototype structure, calculation, and test results.

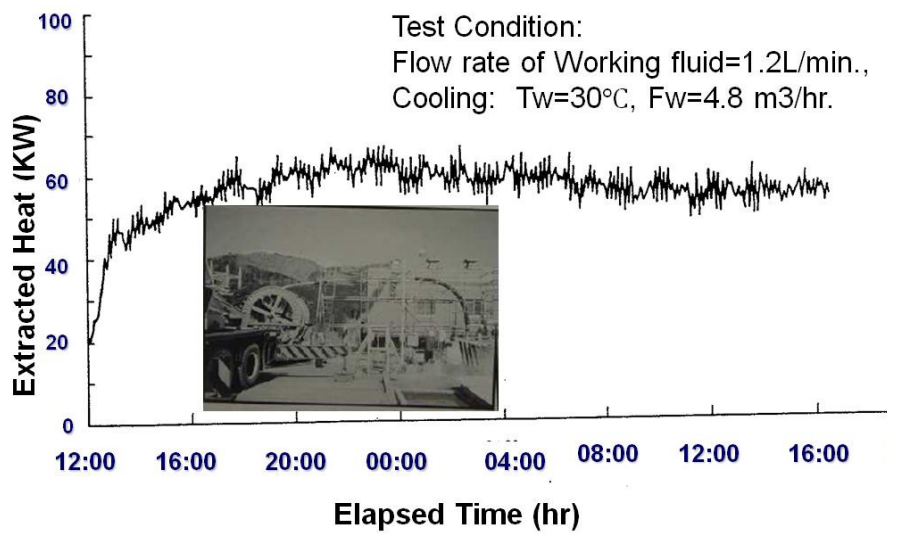

Fig. 46 Test results for geothermal heat extraction by a large-scale heat pipe (diameter $150 \mathrm{~mm}$ and $150 \mathrm{~m}$ long)

\subsection{Case study 5 - Ultra large heat pipes for cooling the earth}

As mentioned before, global warming and protection of earth's environment have been hot topics of concern to all countries. The rise in $\mathrm{CO}_{2}$ production thus the rise in the earth's temperature may have been the cause of increased natural disasters in recent years. One idea to prevent the rise in the earth's temperature is to use an ultra-largescale heat pipe to dissipate the heat generated from people to outer space. Table 3 shows heat-transfer capability vs heat pipe size. For example, a $10-\mathrm{km}$-long heat pipe of diameter $1 \mathrm{~km}$ is capable of transferring $1 \times 10^{11} \mathrm{~W}$. Figure 47 shows an example of energy consumption in Japan. Let us assume that the world's energy consumption is 20 times that of Japan. The calculation shows that it requires about one heat pipe of diameter $1 \mathrm{~km}$ and $10 \mathrm{~km}$ length to transfer all the world's heat generation to outer space.

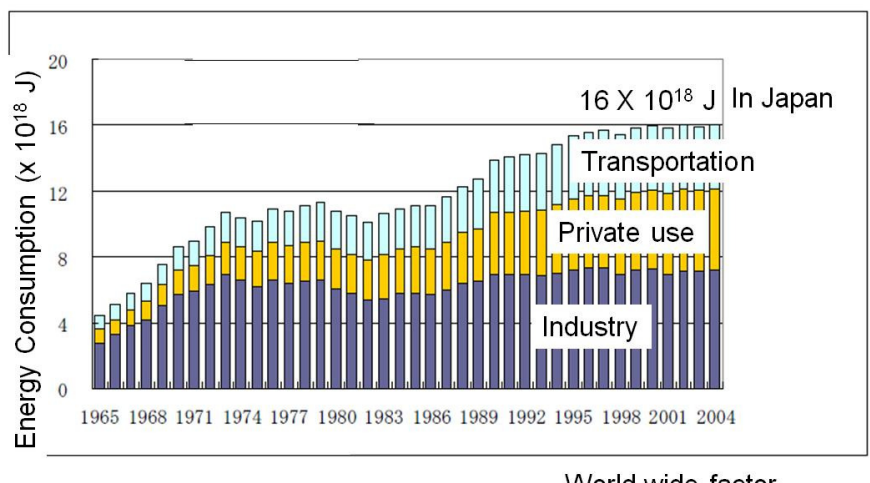

World wide factor

$16 \times 10^{18} \mathrm{~J} /\left\{(365 \times 24 \times 3,600) \times 20 \times\left(\pi / 4 \times(1,000 \times 100)^{2} \times\right.\right.$ $\left.\left.1 \mathrm{Kw} / \mathrm{cm}^{2} \times 1000\right)\right\}=1.2$ pcs Heat Pipes

Fig. 47 Example of energy consumption in Japan

Figures 48 and 49 show the concept and basic design of the ultralarge-scale heat pipe to transfer heat to outer space. The primary heat pipe is a pipe of $1 \mathrm{~km}$ diameter and $10 \mathrm{~km}$ in height, that contains magnetic fluid, and there are plasma rings on the external body. The 
primary heat pipe extracts the heat from the ground and transfers the heat upward. There are multiple secondary heat pipes attached at the upper end of the primary heat pipe that spread the heat to the radiators.

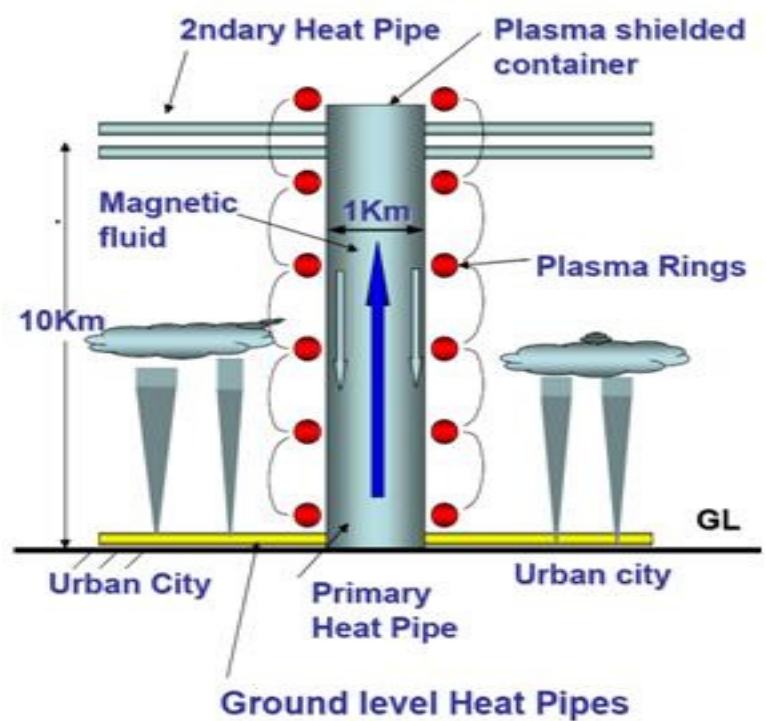

Fig. 48 Concept of ultra-large scale heat pipe for cooling the earth

Table 3 Heat transfer capability vs heat pipe sizes

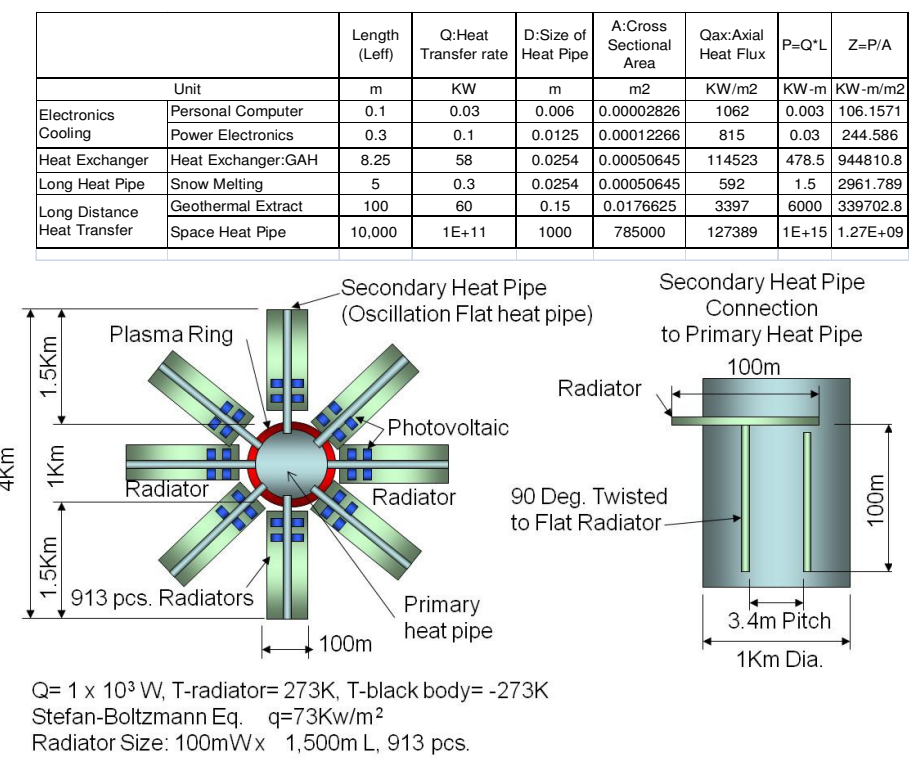

Fig. 49 Design of ultra-large scale heat pipe for cooling the earth
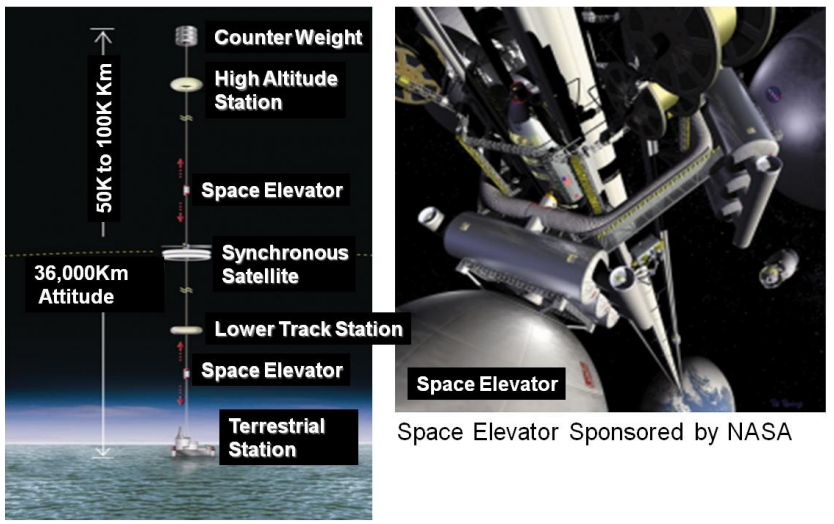

Space Elevator Sponsored by NASA
The ultra-large-scale heat pipe for cooling the earth may seem like an impractical dream, but the authors believe it is feasible. This concept is much less challenging than the 'space elevator' concept shown in Fig. 50 , NASA's dream for commuting between earth and $100 \mathrm{~km}$ into space.

\section{CONCLUSION}

- The computer processor's die surface where heat generation is usually small and heat dissipation is large requires a large space for cooling. The most effective way to transfer heat from the heat source to dissipation area is to use heat pipes or vapor chambers. The use of heat pipes in the metal base or vapor chambers as base helps to reduce thermal spreading at the base. Therefore, the cooling capacity can be increased.

- As the processor power increases and thus the required lower thermal resistance $\left(\mathrm{R}_{\mathrm{ca}}\right)$, the tendency of the cooling solution technology to maximize and extend air cooling has moved towards more use of heat pipes and vapor chambers. Processor heat dissipation will continue to increase owing to the demand for higher and faster processors, and therefore to provide adequate cooling, it is essential to continue research and develop superior heat pipes and vapor chambers having high heat flux capability and minimal possible thermal resistance between heating and cooling ends.

- The thermal resistance from the CPU's die to the IHS comprised a significant ratio of overall thermal resistance. Therefore, there is a need to consider replacing the metal $\mathrm{Cu}$ IHS with some other high heat transfer device such as MVC. In additional direct brazing or soldering the IHS to the CPU's die need to be considered.

- A novel concept for thermal management of data centers on the basis of heat-pipe-based cold water storage, which can help to minimize the thermal load on chiller units and thus save electricity and associated costs. It is a compact cold-energy-storage system for small, as well as large-size data centers and is a more likely option for locations with yearly ambient temperature below the cold storage water temperature. With the massive electricity usage necessary for today's data centers, the cold-energy-storage-based thermal management system can help to address the energy crisis and global warming faced by the world at present.

- In cold regions, the cold energy available in the cold seasons can be collected and used for some applications without the need for electricity, for example, the cooling of data centers, or cooling and storage of agricultural products, or it can be used in any application that requires some form of cooling.

- Hot energy such as solar heat, geothermal heat, or industrial waste heat can be used for practical applications. For example, solar heat can be used for electricity generation or simply for snow melting on road surfaces.

- The ideas for using heat pipes to make these abundant natural energy sources useful are unlimited. The global warming crisis is real and threatens the earth's environment and inhabitants, so it is a responsibility for all countries and individuals to try to reduce and prevent further damages.

- The authors believe that more development is essential for extremely small-and-large-size heat pipes, ie. microscale heat pipes for computers and electronics applications, and large-size heat pipes in kilometers scale for terrestrial and space applications.

\section{REFERENCES}

Brill, K.G., 2010 Heat Density Trends in Data Processing, Computer Systems, and Telecommunications Equipment: Perspectives, Implications, and the Current Reality in Many Data Centers, The Uptime Institute, 2005.

Fig. 50 Space elevator by NASA 
Mashiko, K., Mochizuki, M., Watanabe, Y., Kanai, Y., Eguchi, K., and Shiraishi, M., Proc. of the Fourth Int'l. Heat Pipe Symp., University of Tsukuba, May 16-18, 1994, Japan.

Mochizuki, M., Nguyen, T., Agata, H., and Kiyooka, F., "Advanced Thermal Solution Using Vapor chamber Technology For Cooling High Performance Desktop CPU In Notebook Computer", The $1^{\text {st }}$ International Symposium on Micro \& Nano Technology, 4-7 March 2004, Honolulu, Haiwai, USA.

Mochizuki, M., Nguyen, Thang., Saito, Y., Wuttijumnong, V., Wu, X., Nguyen Tien, "Revolution in Fan Heat Sink Cooling Technology to Extend and Maximize Air Cooling for High Performance Processor in Laptop/Desktop/Server Application”, ASME Summer Heat Transfer Conference \& InterPACK '05, July 17-22, 2005, San Francisco, USA.

Mochizuki, M., Nguyen, Thang., Saito, Y., Kiyooka, K., Wu, X., Nguyen, Tien., and Wuttijumnong, V., "Advance Cooling Chip by Heat Pipes and Vapor Chamber", $14^{\text {th }}$ International Heat Pipe Conference (14 ${ }^{\text {th }}$ IHPC), April 22-27, 2007, Florianopolis, Brazil.

Moore, J., Sharma, R., Shih, R., Chase, J., Patel, C., and Ranganathan, P., "Going beyond CPUs: The potential for temperature-aware data centers,", Proc. of the First Workshop on Temperature-Aware Computer Systems, 2004.

Nguyen, T., Mochizuki, M., Mashiko, K., and Saito, Y., "Advanced Heat Sink Combined With Heat Pipe For Cooling PC", Proc. of the $4^{\text {th }}$ JSME-KSME Thermal Engineering Conference, October 1-6, 2000, Kobe, Japan.
Patel, C.D., Sharma, R., Bash, C.E., and Beitelmal, A., "Thermal considerations in cooling large-scale high compute density data centers," Proc. of the 2002 Inter Society Conf. on Thermal Phenomena, IEEE, 2002.

Saito, Y., Mochizuki, M., Hasegawa, M., Suzuki, T., Amano, K., and Tomojiri, S., Proc. of the Fourth Int'l. Heat Pipe Symp., University of Tsukuba, May 16-18, 1994, Japan.

Sauciuc, I., Moon, S., Chiu, C., Chrysler, G., Lee, S., Paydar, R., Walker, M., Luke, M., Mochizuki, M., Nguyen, T., and Takenaka, E., "Key Thermal Challenges for Low Form Factor Thermal Solution", Semitherm 2005, March 2005, Dallas, USA.

Schmidt, R.R., Crus, E.E., and Lyengar, M.K., "Challenges of data center thermal management," IBM J. Res. Dev., 49(4/5) July/Sept, 2005, page 709 .

doi:10.1147/rd.494.0709

Schmidt, R., Iyengar, M., Steffes, J., and Lund, V., "Co-generation, grid independent power and cooling for a data center," Proc. of ASME 2009 InterPACK Conf., IPACK 2009, July 19-23, 2009, San Francisco, CA, USA.

Singh, R., Akbarzadeh, A., Mochizuki, M., Nguyen, T., and Wuttijumnong, V., "Experimental Investigation of the Miniature Loop Heat Pipe with Flat Evaporator", ASME Summer Heat Transfer Conference \& InterPACK '05, July 17-22, 2005, San Francisco, USA. 